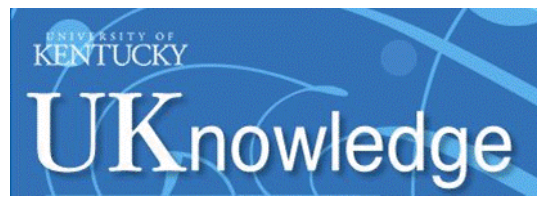

University of Kentucky

UKnowledge

\title{
Pore Functionalized PVDF Membranes with In-Situ Synthesized Metal Nanoparticles: Material Characterization, and Toxic Organic Degradation
}

\author{
Hongyi Wan \\ University of Kentucky, hongyi.wan@uky.edu \\ Nicolas J. Briot \\ University of Kentucky, njbr222@uky.edu \\ Anthony Saad \\ University of Kentucky, anthony.saad@uky.edu \\ Lindell E. Ormsbee \\ University of Kentucky, lindell.ormsbee@uky.edu \\ Dibakar Bhattacharyya \\ University of Kentucky, db@uky.edu
}

Follow this and additional works at: https://uknowledge.uky.edu/cme_facpub

Part of the Chemical Engineering Commons, and the Materials Science and Engineering Commons Right click to open a feedback form in a new tab to let us know how this document benefits you.

\section{Repository Citation}

Wan, Hongyi; Briot, Nicolas J.; Saad, Anthony; Ormsbee, Lindell E.; and Bhattacharyya, Dibakar, "Pore Functionalized PVDF Membranes with In-Situ Synthesized Metal Nanoparticles: Material Characterization, and Toxic Organic Degradation" (2017). Chemical and Materials Engineering Faculty Publications. 62. https://uknowledge.uky.edu/cme_facpub/62

This Article is brought to you for free and open access by the Chemical and Materials Engineering at UKnowledge. It has been accepted for inclusion in Chemical and Materials Engineering Faculty Publications by an authorized administrator of UKnowledge. For more information, please contact UKnowledge@lsv.uky.edu. 


\section{Pore Functionalized PVDF Membranes with In-Situ Synthesized Metal Nanoparticles: Material Characterization, and Toxic Organic Degradation}

\section{Digital Object Identifier (DOI)}

https://doi.org/10.1016/j.memsci.2017.02.021

\section{Notes/Citation Information}

Published in Journal of Membrane Science, v. 530, p. 147-157.

(C) 2017 Published by Elsevier B.V.

This manuscript version is made available under the CC-BY-NC-ND 4.0 license https://creativecommons.org/licenses/by-nc-nd/4.0/.

The document available for download is the author's post-peer-review final draft of the article. 


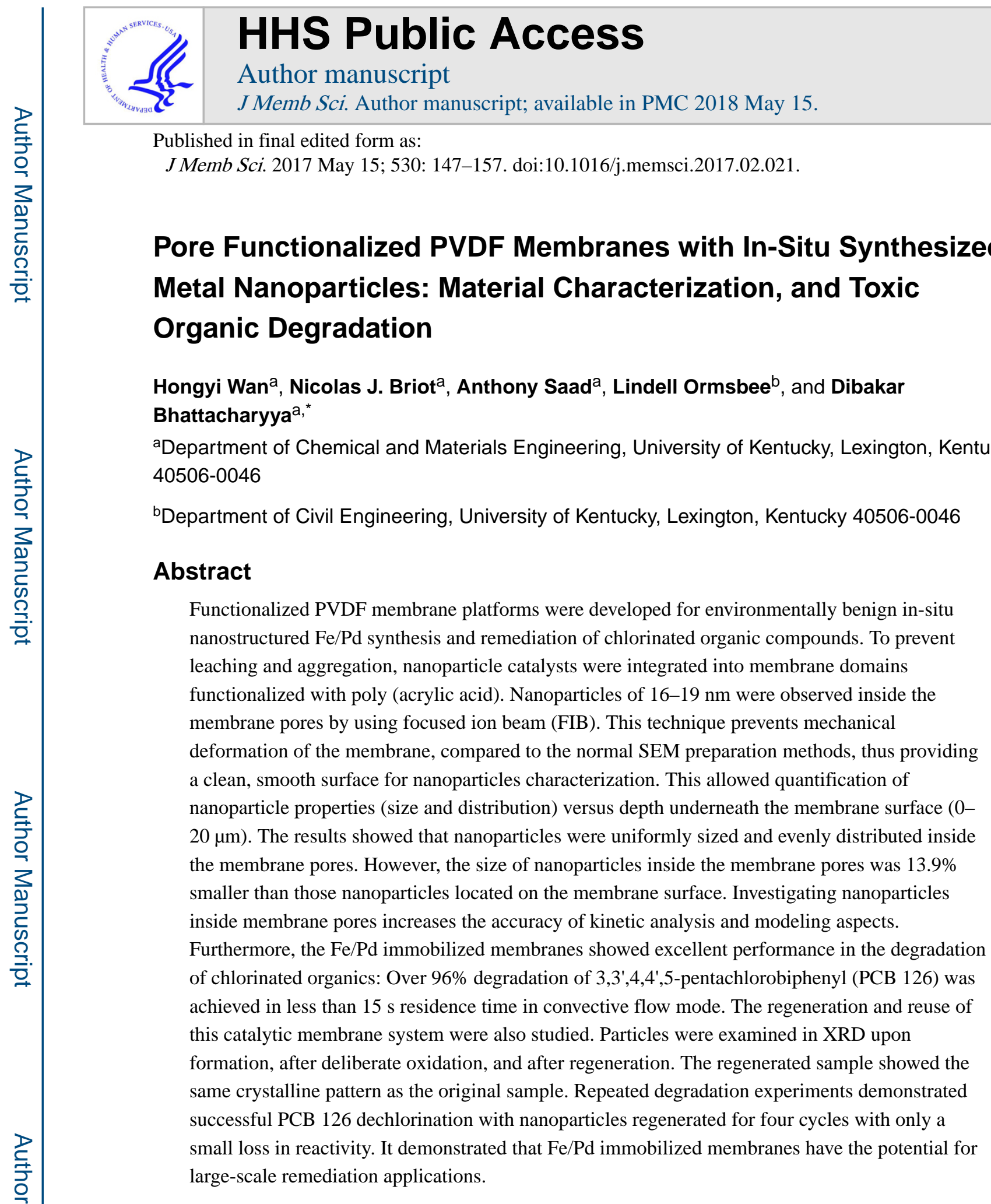

Keywords

Catalysis; PCB Dechlorination; Water Remediation; Fe and Pd; FIB

*Corresponding author: Dibakar Bhattacharyya, University Alumni Chair Professor, Chemical and Materials Engineering, 177 FPAT Bldg., University of Kentucky, Lexington, KY 40506, Phone: 859-257-2794; db@uky.edu. 


\section{Introduction}

Polyvinylidene fluoride (PVDF) membranes, due to their excellent chemical resistance and mechanical properties, are largely used in microfiltration and ultrafiltration processes.

Functionalized PVDF membranes can be used in advanced water separation and environmental remediation with surface modification (e.g., immobilized nanomaterials [1], dip coating [2], layer by layer assembly [3], and surface grafting [4]) and development of various membranes (e.g., blend membranes [5], thin film nanocomposite membranes [6] and electrospinning membranes [7]). In the field of environmental remediation, chlorinated organic compounds (COCs) in groundwater, soil and sludge are of global concern due to their high toxicity, chemical persistence and prevalence in the environment. Once entering the environment, COCs will accumulate in the water, air and biosphere. The biomagnification of some COCs (e.g., polychlorinated biphenyl (PCB), chlorophenol, and trichloroethylene) in the food chain and water can eventually cause harm to human health [8].

Zero-valent iron (ZVI) $[9,10]$ and iron based bimetallic nanoparticles [11-16] have been extensively investigated in the treatment of COCs. Commonly, ZVI nanoparticles have been synthesized by reducing ferrous iron or ferric iron in aqueous solution with sodium borohydride $\left(\mathrm{NaBH}_{4}\right)$ or "green" reducing agent, such as tea polyphenols [17]. However, the large specific surface area of newly prepared ZVI nanoparticles makes them susceptible to oxidation by dissolved oxygen and water, which leads to the formation of iron oxide particles or even iron-based suspensions, as well as to aggregation, which leads to the formation of bulky micro-scale particles. Both iron oxidation and nanoparticle aggregation reduce the reactivity of ZVI nanoparticles, thus hindering wide scale implementation. Many studies have been conducted to control iron nanoparticle size and improve their stability [18-22].

Noble metal can be introduced to enhance the reactivity and broaden the application of ZVI $[23,24]$. With the addition of palladium, a well-known hydro-dechlorination catalyst, one of the most common and stable COCs (i.e., PCB) can be treated. Chemical redox reaction approaches using either iron bimetallic nanoparticles and persulfate [25-35] have shown merit compared to physical adsorption [36] and biological degradation [37] with regard to overall degradation capacity, efficiency and ease of operation. For the Fe/Pd method [12, 3135], Fe is used as an electron source and Pd as a catalyst. Hydrogen, once produced from ZVI corrosion in water, is activated by Pd to form hydrogen radical species. Highly reactive hydrogen radicals then serve as effective electron donors for PCB degradation. This method works whether Pd is coated on ZVI or is present as a separate nanoparticle [11]. Researchers have demonstrated the functionality of this approach by injecting stabilized $\mathrm{Fe} / \mathrm{Pd}$ nanoparticles suspension into a PCB contaminated aquifer [35].

However, without an appropriate platform, the Fe/Pd nanoparticles method faces difficulties with recycling and reuse. In order to prevent nanoparticle aggregation and allow for collection and regeneration, nanoparticle catalysts have been integrated into membrane domains for reaction and reuse. Various of methods, such as the sol-gel process [38, 39], ion-exchange method [40], and in situ reduction [41], were reported for in situ preparation of 
nanoparticle-based membrane systems [42]. In our previous work, we have already reported the in-situ synthesis of iron-based nanoparticles (including ZVI, iron bimetallic, and iron oxide nanoparticles, in poly (acrylic acid) (PAA)-polyvinylidene fluoride (PVDF) membranes), as well as their application in trichloroethylene and PCB treatment [33, 34]. Carboxylate groups from PAA can chelate with metal ions, thereby preventing metal ion loss (i.e., recapture by ion exchange) and nanoparticle aggregation [43]. Tunable membrane pores can be achieved by changing environmental $\mathrm{pH}$ through ionization of carboxylate groups from PAA $[44,45]$.

Understanding the properties of nanoparticles on and underneath the membrane surface is important for investigation of reactivity, anti-bacterial properties and effects on membrane hydrophilicity [46-48]. However, normal SEM preparation techniques (sectioning, fracturing) usually alter the structure of the region of interest, resulting in the characterization of damaged surfaces. Consequently, proper observation of nanoparticle properties, such as size, distribution, configuration and composition, can only be observed on a membrane's surface or external sides rather than deep inside the membrane pores.

Energy-dispersive X-ray spectroscopy (EDX) can be used to prove metal nanoparticles were not only immobilized on the membrane's outer surface, but also distributed inside the membrane [46]. However, the size and configuration cannot be clearly observed in the EDX. In contrast, cross sectioning the membrane using focused ion beam (FIB) technique prevents mechanical deformation of the membrane and can provide a clean, smooth surface for nanoparticles characterization $[49,50]$. All the preparation processes take place in a high vacuum in a FIB/SEM chamber, thereby keeping oxidation of the nanoparticles to a minimum. Furthermore, thin lamella can be lifted out from precise location of the main samples and thinned down for subsequent analysis in the SEM. The correlation between $\mathrm{Fe} / \mathrm{Pd}$ nanoparticle properties (size and distribution) and the depth within the membrane can then be quantified. This correlation is important in investigating the reactivity of $\mathrm{Fe} / \mathrm{Pd}$ immobilized membranes for further degradation studies.

In order to be able to develop reusable Fe/Pd-PAA-PVDF membranes for PCB degradation, it is important to investigate the $\mathrm{Fe} / \mathrm{Pd}$ nanoparticle size and distribution inside membranes.

In the previous study, the membranes were functionalized by immersing in the solvent-based polymer solution before heat treatment. Fe/Pd particle size in the membrane was analyzed in TEM by ultrasectioning cross-section slices with diamond knife. The characterization results were used in a packed bed model simulation of PCB degradation. Model compounds of mono-, bi- and tetra-chlorobiphenyl (PCB 1, PCB 4 and PCB 77) have already been investigated [51]. In this study, PCB 126 (3,3',4,4',5-pentachlorobiphenyl), one of the most toxic and persistent PCB congeners with dioxin-like properties, was chosen as the model compound. The novelty of this research and the objectives are: (1) In-situ synthesis of PAA functionalized PVDF membranes in water-based system for stable immobilization and size control of Fe/Pd nanoparticles; (2) Understanding the correlation between $\mathrm{Fe} / \mathrm{Pd}$ nanoparticle properties (size and distribution) and depth within functionalized membranes by using FIB; (3) Investigation of PCB 126 degradation kinetics; and (4) Demonstration the feasibility of $\mathrm{Fe} / \mathrm{Pd}$ particle regeneration and investigation of the reusability of Fe/Pd-PAAPVDF membranes for PCB 126 degradation. 


\section{Materials and Methods}

\subsection{Chemicals}

The following chemicals were used as received: sodium borohydride (99.99\%), acrylic acid (99\%), PAA powder $\left(\mathrm{M}_{\mathrm{W}}=2000\right)$ and palladium (II) acetate (98\%), naphthalene_d 8 (99 atom $\% \mathrm{D}$ ) were purchased from Sigma-Aldrich. Sodium hydroxide $(1 \mathrm{M})$, sulfuric acid (0.5 $\mathrm{M})$, hexanes and ferrous chloride tetrahydrate were obtained from Fisher Scientific. PVDF powder was purchased from Polysciences, Inc. Ammonium persulfate (98\%), and N,N'methylenebisacrylamide (NNMA, 99\%) were received from Acros Organics. 3,3',4,4',5pentachlorobiphenyl (> 97\%, neat), biphenyl (> 97\%, neat) and their analytical solution (100 ppm in hexane) were obtained from Ultra Scientific. Ethanol (200 proof) was bought from EMD Millipore Corporation. Sodium chloride was purchased from BDH. Full scale PVDF 700 microfiltration membranes were obtained from Nanostone Water, Inc. Deoxygenated water was obtained by purging $\mathrm{N}_{2}$ into deionized ultra-filtered (DIUF) water for 30 minutes.

\subsection{Synthesis Methods}

2.2.1 Synthesis of PAA-PVDF Membranes-Full scale PVDF membranes were functionalized using acrylic acid directly polymerized inside the membrane pores. In our previous work, PAA tended to form a thin layer on the top of the membrane surface and block membrane pores, when immersing membrane in the polymer solution before heat treatment [52]. To diminish the formation of the PAA top layer, the PVDF membrane was placed in a Büchner funnel, which was then connected to a Büchner flask with a tube (Fig. 1). Polymer solution ( $20 \mathrm{ml}$ acrylic acid, $1 \mathrm{~mol} \%$ ammonium persulfate as initiator, $1 \mathrm{~mol} \%$ NNMA as cross-linker and $30 \mathrm{ml}$ deoxygenated water) was drawn through the membrane by vacuum suction ( 0.17 bar vacuum). The permeate polymer solution was then collected and reused through the membrane three times. The excess polymer solution remaining on the membrane surface was swept away using a stream of nitrogen gas. In order to proceed with the polymerization reaction, glass plates were used to sandwich the membrane before transferring it into an oven at $70{ }^{\circ} \mathrm{C}$ for 1 hour with $\mathrm{N}_{2}$ protection. In this process, it is important to remove $\mathrm{O}_{2}$ because it is an inhibitor of the reaction. After polymerization, PAA functionalized membranes were washed with water and then ethanol.

\subsubsection{Fe/Pd Nanoparticles Immobilized in Functionalized Membranes-Fe/Pd}

nanoparticle immobilization consisted of three steps: ion exchange, iron reduction and palladium coating. The first two steps were achieved by following methods developed in our lab [33]. Functionalized PAA-PVDF membranes were soaked overnight in $500 \mathrm{ml} \mathrm{NaCl}$ solution $(68.4 \mathrm{mM})$ for $\mathrm{Na}^{+}$exchange, in order to increase the ability of further $\mathrm{Fe}^{2+}$ exchange. This resulted in a decrease in the $\mathrm{pH}$ of the solution because carboxyl groups chelated with $\mathrm{Na}^{+}$and released $\mathrm{H}^{+}$simultaneously. As a result, $\mathrm{NaOH}$ was added to maintain $\mathrm{pH}$ around 10 in order to increase the loading of $\mathrm{Na}^{+}$. Membranes were washed with deoxygenated water and then soaked in $\mathrm{FeCl}_{2}$ solution $(3.57 \mathrm{mM}, \mathrm{pH}=5.3)$ for a second ion exchange. This process was operated in an oxygen free environment for 4 hours. $\mathrm{Fe}^{2+}$ was reduced to $\mathrm{Fe}^{0}$ by immersing the membranes in a $\mathrm{NaBH}_{4}$ solution $(26.4 \mathrm{mM})$. After being washed by water and ethanol three times, Fe-PAA-PVDF membranes were immersed in $\mathrm{Pd}(\mathrm{OAc})_{2}$ ethanol solution for Pd coating which was achieved by vigorous 
shaking for 2 hours. The resulting functionalized membranes were then washed and saved in pure ethanol.

\subsection{Characterization of Functionalized Membranes and Immobilized Nanoparticles}

2.3.1 Membrane Surface Morphology-The surface morphology of the membranes was studied using a scanning electron microscope (SEM, Hitachi S-4300). Membrane samples were dried and freeze fractured in liquid nitrogen before being sputter coated with platinum. Membrane pore size and surface porosity were analyzed with ImageJ software.

2.3.2 PAA Functionalization-Attenuated total reflectance Fourier transform infrared spectroscopy (ATR-FTIR, Varian 7000e) was used to validate the successful functionalization with PAA qualitatively. The spectrum ranged between 500 and $4000 \mathrm{~cm}^{-1}$ for 32 scans. PVDF powder, PAA powder, full scale PVDF membranes and PAA functionalized membranes were all analyzed.

The membrane contact angle was measured using drop shape analyzer (DSA 100, Krüss). For PAA functionalized membranes, it is difficult to measure the contact angle of hydrophilic surfaces via sessile drop due to their high surface free energy, which causes the water droplet to rapidly spread [53], as well as the fast absorption of water by PAA hydrogel. The captive bubble method was used to obtain more consistent results and decrease the measurement errors due to preparation conditions in the sessile drops method [54, 55]. Instead of squeezing a water droplet onto the membrane surface, the membrane was immersed in DI water and an air bubble was then injected beneath the surface. At least 15 bubbles were measured per sample.

2.3.3. Synthesis and Regeneration of Fe/Pd particles-In order to test the feasibility of Pd coating by zero-valent iron reduction and the possibility of particles regeneration, $\mathrm{Fe} / \mathrm{Pd}$ particles were synthesized, oxidized and regenerated in solution phase for X-ray diffractometer (Siemens D500) analysis with $\mathrm{Cu} \mathrm{Ka} \mathrm{(1.5418} \mathrm{\AA )} \mathrm{radiation}$ (generator voltage of $40 \mathrm{keV}$, tube current of $30 \mathrm{~mA}$ ). All the samples were dried in a vacuum, placed in an aluminum holder, and compressed to form a smooth surface. XRD spectra was obtained between $2 \theta$ angles of $20-100^{\circ}$, with a step size of $0.05^{\circ}$ and a 1 second dwell time. Pure Fe particles were synthesized by dissolving $\mathrm{FeCl}_{2}$ in DI water and then reducing by excess $\mathrm{NaBH}_{4}$. After washing and centrifuging, a portion of the freshly made $\mathrm{Fe}$ particles were dried in vacuum at $50^{\circ} \mathrm{C}$ overnight for XRD analysis, and the remaining $\mathrm{Fe}$ particles were transferred into $20 \mathrm{ml}$ vials containing a $\mathrm{Pd}(\mathrm{OAc})_{2}$ ethanol solution. After shaking for 1 hour, the particles were washed and centrifuged before drying in a vacuum at $50^{\circ} \mathrm{C}$ overnight. Pd particles were made by the same method as Fe particles. Furthermore, with the purpose of testing the regeneration of $\mathrm{Fe} / \mathrm{Pd}$ particles, synthesized $\mathrm{Fe} / \mathrm{Pd}$ particles were deliberately oxidized by immersion in DI water with air bubbling for 2 hours. Oxidized $\mathrm{Fe} / \mathrm{Pd}$ particles were reduced again using $\mathrm{NaBH}_{4}$ method after XRD analysis. XRD results of the freshly made and the regenerated $\mathrm{Fe} / \mathrm{Pd}$ particles were compared to prove the feasibility of regeneration. Iron (III) oxide, one of the main oxides of iron, was tested to compare the crystalline pattern with the deliberately oxidized Fe/Pd particles sample. 


\subsubsection{Size, Distribution and Composition of Fe/Pd Nanoparticles inside the}

Membrane-The size and distribution of the Fe/Pd nanoparticles were studied both on the surface and inside the membrane pores after preparation of a lamella using FIB-SEM (FEI Helios Nanolab 660) analysis. Following surface imaging of the region of interest, a lamella was lifted out of the membrane sample and its thickness gradually reduced using FIB until it was transparent. The specimen was then imaged via scanning transmission electron microscopy (STEM) in the FIB-SEM. Following this treatment, the Fe/Pd nanoparticles inside the membrane pores could then be directly observed in transmission.

The elemental composition of the particles was determined by energy dispersive X-ray spectroscopy (EDX, Oxford Instruments X-Max ${ }^{\mathrm{N}} 80$ detector) on the lamella. Their reduced thickness decreased scattering of the beam and optimized EDX lateral resolution. Although individual nanoparticles could not be distinguished during EDX elemental mapping, regions where particles agglomerated were identified. Elemental composition of this agglomerate was possible, and only $\mathrm{Fe}$ and $\mathrm{Pd}$ were considered during this analysis. Other observed elements such as the C, H, F, O (membrane elements), Pt (coating), $\mathrm{Ga}$ (beam) and $\mathrm{Cu}$ (holder) were ignored to clearly analyze $\mathrm{Fe}$ and $\mathrm{Pd}$ composition.

2.3.5 Metal Loading Analysis-Inductively coupled plasma optical emission spectroscopy (ICP-OES, VARIAN) was used to accurately measure the concentration of metal ion in solution. The amount of absorbed $\mathrm{Fe}$ in the ion exchange process was determined by mass balance after the Fe exchange process. The amount of ZVI and coated $\mathrm{Pd}$ in the membranes were measured by digesting $\mathrm{Fe} / \mathrm{Pd}$ immobilized membranes in dilute nitric acid (20\%) with heat before ICP-OES analysis. Relative to EDX, ICP-OES is more sensitive and could analyze the whole membrane sample rather than just the mapping area in EDX. Therefore, ICP-OES was used to analyze total metal loading of the membrane samples for kinetic analysis.

\subsection{PCB Diffusivity through PAA Functionalized Membrane}

PCB diffusivity through the membrane is important for understanding the influence of PCB mass transport and for the simulation of PCB degradation. In order to investigate the diffusion rate of $\mathrm{PCB}$, two diffusion cells with a thin membrane barrier pressed between the feed side and permeation side were used to measure the rate of PCB penetration through the membrane. A $300 \mathrm{ml}$ ethanol water mixture (V/V = 1/9) was simultaneously added into both sides of the diffusion cells. A concentration of $15 \mu \mathrm{M}$ PCB 126 was then added to the feed side of the membrane. At time zero, PCB 126 began to diffuse from the feed side to the permeation side by penetrating the membrane. The solution in both sides was stirred vigorously during the whole diffusion test. The membrane separating the two sides had an area of $3.46 \mathrm{~cm}^{2}$. The concentration of PCB on both sides of the membrane was measured over time using gas chromatography (Varian CP-3800)-mass spectrometry (Saturn 2200). Triplicate samples were collected by taking $2 \mathrm{ml}$ of solution, followed by extraction with 2 $\mathrm{ml}$ hexanes with internal standard (napathelene_d8) by shaking for 2 hours. 


\subsection{PCB 126 Degradation}

PCB 126 degradation was evaluated in both batch and convective flow mode. PCB 126 was dissolved in absolutely pure ethanol with stirring due to its extremely low water solubility. The batch experiment was conducted in $20 \mathrm{ml}$ EPA glass vials with vigorous shaking (250 $\mathrm{rpm}$ ). Two pieces of functionalized Fe/Pd-PAA-PVDF membranes (surface area of $17.3 \mathrm{~cm}^{2}$ each) were placed in vials $\left(15 \mu \mathrm{M}\right.$ PCB $\left.126, \mathrm{~V}_{\text {ethanol }} / \mathrm{V}_{\text {water }}=1 / 9, \mathrm{pH}=5.5\right)$. The experiment was terminated by removing the membrane pieces from the vials. $20 \mathrm{ml}$ of hexanes was used to extract the organic compounds in the solution phase and the membrane phase separately ( $10 \mu \mathrm{l} 1000 \mathrm{ppm}$ naphthalene_d8 added as internal standard). After 2 hours of shaking, the hexanes phase was analyzed by using GC-MS.

For the convective flow study, a piece of functionalized membrane was put into a dead-end filtration cell. The effective external area was $13.2 \mathrm{~cm}^{2}$. Permeate was collected after 20 minutes when the reaction was observed to approach steady state. Separate samples were then collected at 10 minute intervals while varying the operating pressure. Triplicate samples were collected for GC-MS analysis. In this case, residence time (the average time of particles spent in the membrane) was varied by changing the pressure applied in the filtration cell (1.38 bar to 8.96 bar).

Reusability was further tested. The regeneration process consisted of washing membranes with ethanol three times after extraction and then soaking the membranes in a $100 \mathrm{ml} 0.026$ $\mathrm{M} \mathrm{NaBH}_{4}$ solution for 5 minutes. Regenerated membranes were washed by deoxygenatedDI water before being reused in the degradation study. The degradation study was reproduced with regenerated membranes under the same initial conditions. The degradation extent of PCB and the size of nanoparticles were analyzed after every cycles.

\section{Results and Discussion}

A brief schematic illustrating the specific aims of this work and corresponding results discussion processes is shown in Fig. 2.

\subsection{Membrane Functionalization and Properties}

Changes in the membrane properties after the PAA functionalization process (such as contact angle, thickness, permeability, etc.) are summarized in table 1. Functionalization of the PAA increased the membrane hydrophilicity which decreased the risk of fouling. Growth of the PAA layer on top of the membrane resulted in an associated growth of the total membrane thickness. Using the current synthesis approach, a thinner PAA layer was produced and decreased the likelihood of clogging. The resulting membrane pore size and surface porosity (35.4\%) were observed by SEM and further analyzed by ImageJ software. As shown in the resulting SEM image (Fig. S. 1), the PAA domain occupied the membrane pores and decreased the membrane pore size. This decrease in the pore size changed the membrane permeability, which confirmed the successful functionalization in the membrane pores.

In order to confirm the stability of the PAA domain within the membrane pores, the permeability of the PAA functionalized membranes was tested over a seven-day period at 
two different values of $\mathrm{pH}$ (i.e., 3.1 and 11.2). Permeability is affected by $\mathrm{pH}$ value because of the ionization of the carboxylate groups in PAA domain. Increasing $\mathrm{pH}$ ionizes the carboxylate groups, which causes the polymer chain to swell in the presence of water, thereby leading to a decrease in both membrane pore sizes and flux. During the permeability test, the feed solution was allowed to flow through the membrane continuously for seven days at a pressure of 2.76 bar. The flux was measured from time to time during the day for seven days. The resulting permeability measurements are shown in Fig. 3 (a). The permeability was $16.9 \pm 0.9 \mathrm{LMH} / \mathrm{bar}$ at $\mathrm{pH} 3.1$ and $3.4 \pm 0.2 \mathrm{LMH} / \mathrm{bar}$ at $\mathrm{pH} 11.2$. Each data point in the figure represents an average of at least three independent flux measurements. The coefficient of variation is 0.053 and 0.058 at $\mathrm{pH} 3.1$ and $\mathrm{pH} 11.2$ respectively. The small values of the coefficient of variation clearly indicates the long term stability of the functionalized membrane in both acidic and alkaline environments.

Furthermore, membrane $\mathrm{pH}$ reversibility was tested at $\mathrm{pH} 3.1$ and $\mathrm{pH} 11.2$. After treating the membranes with a particular $\mathrm{pH}$ solution, flux measurements were recorded. The results of the pH reversibility study are shown in Fig. 3 (b). The permeability of the membrane regained its original value (with minor variances) when the membrane was exposed to the original $\mathrm{pH}$ environment. The variances in the permeability can be explained by the way that the PAA domain develops inside the pores. The PAA are bound to the membrane pores without any covalent bond connectivity and thus form a matrix inside the membrane pores. Because the PAA polymer is not covalently attached to the membrane matrix they are more susceptible to undergo an unorganized swelling (at high $\mathrm{pH}$ ) followed by shrinking (at low $\mathrm{pH}$ ), which in turn might change the original conformation of the polymer domain and membrane pore size distribution after each $\mathrm{pH}$ reversibility study. The ionization of carboxylate group from PAA also changes the hydrophilicity of PAA domain. This observed $\mathrm{pH}$ responsive behavior shows the potential to control the extent of absorption for organic contaminants thus having effects on the observed reaction rate of degradation. Application need to be further investigated.

Rather than visually observing the physical changes of membrane properties, infrared spectroscopy analysis was conducted to provide a more qualitative confirmation of successful PAA functionalized in the membrane pores. In Fig. S. 2, CF/CF 2 bond stretching appears in $1160 \mathrm{~cm}^{-1}$, this peak shown in the PVDF powder, the original PVDF membrane and the PAA-PVDF membrane samples. Compared to the PVDF powder sample, the PAA powder sample had several characteristic peaks: the absorption peak at $1700 \mathrm{~cm}^{-1}$ is associated with acid $\mathrm{C}=\mathrm{O}$ stretching, and the broad band observed at $2500-3300 \mathrm{~cm}^{-1}$ is caused by the stretching vibration of $\mathrm{O}-\mathrm{H}$ groups. Both of these peaks were observed in the PAA-PVDF membrane sample but not in the original PVDF membrane sample, which proved the successfully functionalization of PAA in the PVDF membranes.

\subsection{Properties of Fe/Pd Nanoparticles inside the Membrane Pores}

$\mathrm{Fe} / \mathrm{Pd}$ nanoparticles were successfully immobilized in the membrane and their size was controlled by the cross-linked structure of the PAA domain. Nanoparticle distribution was determined not only on the surface, but also deeper within membrane pores by FIB-SEM. Furthermore, after characterization via FIB-SEM at various depths under the membrane 
surface, the relation between nanoparticles properties (size and distribution) and the depth within the membrane was quantified. The size and distribution were statistically analyzed with the help of ImageJ software. The nanoparticle composition was then quantitatively tested by EDX and ICP-OES.

The size of nanoparticles was measured by FIB-SEM at various depths within the membrane from 0 to $17.8 \mu \mathrm{m}$ (Fig. 4, Fig. 5). With the assist of ImageJ software, the particle size distribution on the surface was automatically obtained and summarized after the examination of more than 500 nanoparticles (Fig. 4). About $94.5 \%$ of the particles were distributed in the range of $15-25 \mathrm{~nm}$ and the particles had a mean size of $19.4 \mathrm{~nm}$ with standard deviation of $3.2 \mathrm{~nm}$. For those particles inside the membrane pores, FIB was applied to prepare a crosssection lamella sample under the membrane surface (Fig. S. 3). Since the images were captured in transmission, the particles were visible through the membrane. However, this prevented proper edge recognition during subsequent automated imaging software analysis. Therefore, nanoparticles size inside the membrane pores were analyzed (more than 200 counts) by manually selecting the particles in the image (Fig. 5). As shown in Fig. 6, particle size was uniform inside membrane pores at different depths (particle size: $16.7 \pm 0.7 \mathrm{~nm}$ ) but smaller than those nanoparticles located on the surface $(19.4 \pm 3.2 \mathrm{~nm})$. The surface coverage values are the occupation of immobilized nanoparticles to membrane matrix. For example, the surface coverage value of the FIB modified area in Fig. 5 (d) was calculated to be 0.175 by the total nanoparticle area $\left(0.118 \mu \mathrm{m}^{2}\right)$ over the membrane matrix area $(0.673$ $\mu \mathrm{m}^{2}$ ), which was obtained by the difference between the membrane domain area and the membrane pores. Therefore, these fairly similar surface coverage values demonstrated the evenly distributed nanoparticles inside the membrane pores. Because of the ratio of the thin PAA surface layer to the whole thickness of membrane sample as well as the negligible deviation of nanoparticles size and their distribution along the depth inside the membrane pores, it is reasonable to assume that the nanoparticle properties, used in kinetic analysis, were appropriately simplified and regarded as uniform. Considering the limitation of the lamella sample dimensions inherent to the FIB preparation technique, including total volume of the sample to mill, lamella structural cohesion during thinning (a less than $100 \mathrm{~nm}$ thin lamella with the length of 100-1000 times), nanoparticle characterization inside the membrane pores were conducted to a depth less than $20 \mu \mathrm{m}$ rather than the entire membrane thickness for this study.

\subsection{Synthesis and Regeneration of Fe/Pd Particles}

In order to demonstrate the feasibility of using Pd coating and the potential for regeneration of $\mathrm{Fe} / \mathrm{Pd}$ particles, $\mathrm{Fe}, \mathrm{Pd}$, and $\mathrm{Fe} / \mathrm{Pd}$ particles were synthesized and then analyzed by XRD. The crystalline structure of $\mathrm{Fe}, \mathrm{Fe}_{2} \mathrm{O}_{3}$ and $\mathrm{Pd}$ were analyzed and confirmed through comparison with XRD patterns published in the literature [56-58]. In Fig. 7, the crystalline phases of monometallic Fe and Pd particles were also present in the synthesized bimetallic $\mathrm{Fe} / \mathrm{Pd}$ sample. It demonstrated the successful coating of Pd in Fe particles. Furthermore, the dominant (110) peak of metallic iron disappeared after deliberate oxidization treatment (air bubbling) but the dominant (111) peak of palladium remained. Several peaks indicating the formation of $\mathrm{Fe}_{2} \mathrm{O}_{3}$ appeared in this oxidized sample, however, these peaks disappeared after the oxidized sample was reduced by $\mathrm{NaBH}_{4}$. The crystalline patterns of $\mathrm{Fe}$ and Pd were 
recovered after reduction, which is significant. The disappearance of $\mathrm{Fe}_{2} \mathrm{O}_{3}$ peaks and the recovery of the $\mathrm{Fe}$ and $\mathrm{Pd}$ crystalline patterns demonstrated the regeneration of $\mathrm{Fe} / \mathrm{Pd}$ particles, which is the premise of Fe/Pd-PAA-PVDF membrane regeneration for reuse in PCB degradation.

To identify the formation of Fe/Pd nanoparticles in PAA-PVDF membranes, EDX mapping was performed with high $\mathrm{Pd} / \mathrm{Fe}$ ratio particles. Due to the tiny amount of coated Pd used in the degradation experiment and the limitation of instrument, a larger Pd to Fe ratio was used to overcome the interference from noise for observational purposes in EDX analysis. As shown in Fig. S. 4, Pd was 13.4 wt \% of Fe in mapping area. However, EDX can only test composition in the mapping area, it cannot accurately determine the metal composition in whole membrane sample. Thus, ICP-OES was applied to test the metal content in the whole membrane. After digesting the membrane sample in dilute nitric acid (20\%) with heat, ICPOES showed the amount of $\mathrm{Pd}$ to be $11.2 \mathrm{wt} \%$ of $\mathrm{Fe}$. This high $\mathrm{Pd} / \mathrm{Fe}$ ratio membrane sample was specifically made for comparing the composition results between EDX and ICPOES. In fact, smaller amounts of Pd (1-2 wt \% of Fe) were used in PCB degradation experiment in consideration of the cost of the Pd. Furthermore, ICP analysis showed that the absorption of $\mathrm{Fe}$ (II) to the membrane was $1.8 \times 10^{4} \mathrm{~g} \mathrm{Fe} / \mathrm{m}^{3}$ of the membrane and 98.4 $\pm 1.1 \%$ of absorbed $\mathrm{Fe}$ remained in the membrane after reduction.

\subsection{PCB 126 Diffusivity in Membrane}

The diffusion coefficient of PCB was obtained by applying the equation derived by Yang et al [59].

$$
\frac{C_{\mathrm{PCB}}}{C_{\mathrm{PCB}, \text { initial }}}=\left[\frac{\mathrm{DH}}{l}\right]\left(\frac{A}{V}\right)\left(t-\frac{l^{2}}{6 D}\right)
$$

In this equation, $D$ is diffusion coefficient $\left(\mathrm{m}^{2} \mathrm{~s}^{-1}\right), H$ is partition coefficient, $A$ is the membrane area $\left(\mathrm{m}^{2}\right), V$ is the volume of the solution in permeation side $\left(\mathrm{m}^{3}\right)$ and $l$ is the membrane thickness $(m)$.

The intercept of the horizontal axis, $\mathcal{P} / 6 D$, is regarded as the "lag time". The diffusion coefficient can be easily derived from the lag time. Furthermore, the bulk diffusion coefficient of PCB 126 in an ethanol water mixture solution can be calculated from the Stokes-Einstein equation,

$$
D_{s}=\frac{k_{B} T}{6 \pi \mu r}
$$

where $k_{B}$ is Boltzmann's constant; $\mu$ is the dynamic viscosity of solvent $\left(\mu_{\text {water }}=8.9 \times 10^{-4}\right.$ Pa. $S, \mu_{\text {ethanol }}=10.4 \times 10^{-4} \mathrm{~Pa} \cdot S$, both at $298.15 \mathrm{~K}$ ); and $r$ is the radius of the spherical particle. The parameter $r$ can be calculated for PCB 126 from the molar volume, which is $214.5 \mathrm{~cm}^{3} \mathrm{~mol}^{-1}$. This value was determined using ACD/Labs Percepta Platform - 
PhysChem Module. Using these values, the bulk diffusion coefficient was determined to be $5.58 \times 10^{-10} \mathrm{~m}^{2} \mathrm{~s}^{-1}$ in water and $4.77 \times 10^{-10} \mathrm{~m}^{2} \mathrm{~s}^{-1}$ in ethanol.

The experimental results of the PCB diffusivity test in the functionalized PAA-PVDF membrane is shown in Fig. S. 5. The change of the concentration of PCB in the feed side was negligible and the PCB concentration in the permeation side linearly increased with the diffusion time. The diffusion coefficient of PCB 126 in the functionalized membrane was 1.1 $\times 10^{-12} \mathrm{~m}^{2} \mathrm{~s}^{-1}$ as determined using the derived lag time. This value is less than the one calculated in the water or ethanol solutions. This difference is expected because of the constrains imposed by the functionalized PAA chains and PVDF membrane matrix.

\section{5 РCB 126 Degradation}

PCB degradation experiments were conducted in both batch mode and convective flow mode. Dechlorination activity, mass transport hindrance and membrane reusability were all investigated. In order to test the possible effect of ZVI on the dechlorination process, $\mathrm{Fe}$ loaded functionalized membranes were also studied. As demonstrated before, biphenyl is the main product of $\mathrm{PCB}$ degradation when using the $\mathrm{Fe} / \mathrm{Pd}$ reductive pathway [33, 51]. However, for this coplanar PCB congener (i.e., PCB 126), the biphenyl yield was much lower than the theoretically attainable value. In order to explain this unbalance, biphenyl evaporation, adsorption on the membrane and possible further reactions with $\mathrm{Fe} / \mathrm{Pd}$ immobilized membrane system were investigated.

3.5.1 PCB Degradation Kinetics by Batch Studies-The results from batch study are shown in Fig. 8. Based on the insignificant change in the residual PCB concentration in the blank control samples (no membrane), the evaporation of PCB 126 was assumed to be negligible. Furthermore, the presence of Pd was found to be necessary for any significant PCB degradation; no significant consumption of PCB was observed during the operation time (4 hours) using Fe-PAA-PVDF membranes without Pd. In contrast, with the Pd coating, the concentration of PCB 126 rapidly reduced and 97.5\% PCB 126 was consumed after 4 hours compared to $3.8 \%$ consumed in the Fe-PAA-PVDF samples.

Theoretically one mole of biphenyl should be produced by every mole of dechlorinated PCB 126. Interestingly, the produced biphenyl found in the sample was only $58.1 \%$ of consumed PCB 126 after 4 hours. This imbalance between PCB consumption and biphenyl production was also observed by Choi et al [12]. They found 97\% 2-chlorobiphenyl consumed in 2 days with the granular activated carbon $\mathrm{Fe} / \mathrm{Pd}$ system, however, the observed biphenyl concentration was only $27 \%$ of the initial PCB concentration. The possible explanations for this phenomenon are listed below: (1) formation of PCB intermediates by partial dechlorination of PCB 126; (2) the potential evaporation of the biphenyl formed during the dechlorination process; (3) some of the biphenyl was adsorbed in the membrane and was not completely extracted by the hexanes; (4) biphenyl was further degraded in this system; (5) the target pollutant, intermediates and products were all covered by the sequential formed surface passive layers of $\mathrm{Fe} / \mathrm{Pd}$ nanoparticles, such as ferrous hydroxides, ferric hydroxides or their mixtures, with the increasing $\mathrm{pH}$. The last point is easy to avoid by adding dilute acid before the extraction. 
In order to investigate the production of intermediates, eight possible low-chlorine PCB intermediates (ranging from mono-chlorobiphenyl to tetra-chlorobiphenyl) were tested (Fig. S. 6). However, the total concentration of these eight PCB intermediates was found to be no more than 3\% of initial concentration of PCB 126 at any selected time point. Thus, the formation of PCB intermediates was excluded as a reason for the imbalance. Additionally, $15 \mu \mathrm{M}$ PCB 126 and $15 \mu \mathrm{M}$ biphenyl were tested separately for their evaporation and adsorption tendencies. In the PAA-PVDF membrane samples, PCB and biphenyl remained in both the solution and the membrane phase; therefore, the total residual of these chemicals will be the sum of the chemicals existing in both phases. As shown in Fig. S. 7, although the evaporation of biphenyl was more than the evaporation of PCB, only $4.1 \%$ biphenyl evaporated after 4 hours, which does not account for the perceived loss of biphenyl product. The PCB total residual in the blank control samples (i.e., no membrane) and PAA-PVDF membrane samples had no significant difference (98.5\% and $95.1 \%$, respectively) and most of the remaining PCB was in the solution phase rather than in the membrane phase. In contrast, there was $10 \%$ less biphenyl residue in the PAA-PVDF membrane samples than in the blank control samples. Only $53.5 \%$ of biphenyl in the PAA- PVDF membranes remained in solution phase. This indicates biphenyl was much more likely absorbed by the PAAPVDF membrane causing a decrease in extraction efficiency, which led to incomplete extraction in the membrane phase. Therefore, there was $10 \%$ less remaining biphenyl in the PAA-PVDF membrane samples compared to the non-membrane samples. Furthermore, biphenyl total residue was further decreased with the existence of Fe and Fe/Pd. Only 64.9\% and $56.7 \%$ biphenyl remained after 4 hours in the Fe-PAA-PVDF membrane and the Fe/PdPAA-PVDF membrane samples, respectively (Fig. S. 8). The biphenyl was possibly further degraded by the reactive nanoparticles or the $\mathrm{Fe} / \mathrm{Pd}$ nanoparticles further decreased the extent of extraction.

In batch study, the PCB 126 degradation can be regard as pseudo-first-order reaction:

$$
\frac{\mathrm{dC}}{\mathrm{dt}}=-k_{\mathrm{sa}} \rho_{m} a_{s} C
$$

Where $k_{s a}$ is surface normalized reaction rate $\left(L \cdot m^{-2} h^{-1}\right) \cdot \rho_{m}$ is nanoparticle loading density, which is $0.41 \mathrm{~g} \cdot \mathrm{L}^{-1}, a_{S}$ is surface area per unit mass, which is $45.5 \mathrm{~m}^{2} \mathrm{~g}^{-1}$, calculated from average spherical nanoparticle size $(16.7 \pm 0.7 \mathrm{~nm}$, based on the FIB characterization) and iron density $\left(7870 \mathrm{~g} \cdot \mathrm{L}^{-1}\right)$. The $k_{s a}$ value was determined to be $0.068 \mathrm{~L} \cdot \mathrm{m}^{-2} \mathrm{~h}^{-1}$.

\subsubsection{PCB Degradation Kinetics by Convective Flow Studies-The reaction rate} determined in batch study consists of both a reaction term and a diffusion term. This means that the $k_{s a}$ value determined by the batch study is less than the actual value. However, under a convective flow mode, the influence of mass transfer will decrease with the pressure driven flow thus accelerating the degradation reaction. Therefore, a convective flow study was conducted to investigate the reaction rate for $\mathrm{Fe} / \mathrm{Pd}$ functionalized membranes.

The residence time was calculated by $\tau=V_{\text {void }} /\left(J_{W} A\right)$, where $V_{\text {void }}=V_{\text {matrix }}-V_{N P}=\varnothing V$, and where $J_{W}$ is the pure water flux at specific pressure. $\varnothing$ is surface porosity. $V_{\text {matrix }}$ is the 
space inside membrane pores (based on the weight difference between dry and wet PAAPVDF membranes). $V_{N P}$ is the volume of Fe/Pd particles, which was calculated using the specific metal loading and the average size of particles obtained from the characterization. In Fig. 9, with the increase of residence time, the PCB 126 concentration in the permeate remained unchanged when the PCB penetrated the Fe-PAA-PVDF membrane, which means the absorption and evaporation of PCB 126 can be neglected under convective flow mode. In contrast, the concentration of the PCB in the permeate continuously decreased with the increase of residence time. About $96 \%$ of the PCB was dechlorinated at a residence time of 14.7 seconds. The reaction rate was determined by further kinetic analysis. The results were then compared to the one obtained from batch study leading to the determination of the influence of mass transfer on the degradation process.

Based on the characterization of membrane and $\mathrm{Fe} / \mathrm{Pd}$ nanoparticles, the functionalized membrane is assumed to be a combination of cylindrical pores with uniformly distributed $\mathrm{Fe} / \mathrm{Pd}$ nanoparticles. Furthermore, due to the small Reynolds number $(\operatorname{Re} \ll 1)$, each cylindrical pore could be assumed to be a laminar flow reactor (LFR) [60, 61].

For laminar flow in every cylindrical pores:

$$
u(r)=2 u_{0}\left(1-\frac{r}{R}\right)^{2}
$$

Where $R$ is the pore size of the functionalized membrane. $u_{0}$ and $u(r)$ are the velocities at center and radius $r$, respectively.

Flux through the membrane with surface area $\left(A_{M}=13.2 \mathrm{~cm}^{2}\right)$ and porosity $(\varnothing=35.4 \%)$ :

$$
J_{w}=\frac{n_{\text {pores }} \int_{0}^{R} u(r) 2 \pi \mathrm{rdr}}{A_{M}}=\frac{\varnothing u_{0}}{2}
$$

The mean velocity $(\vec{u})$ at the pores:

$$
\bar{u}=\frac{J_{w} A_{M}}{n_{\text {pores }} \pi R^{2}}=\frac{J_{w}}{\varnothing}=\frac{u_{0}}{2}
$$

The residence time $(\tau)$ for the membrane thickness $(L=70 \mu \mathrm{m})$ is

$$
\tau=\frac{V_{\text {void }}}{J_{w} A_{M}}=\frac{2 L}{u_{0}}
$$

It should be noted that the mean velocity is related to the membrane water permeation flux and is a function of transmembrane pressure. Mass diffusion $\left(D_{M}=1.1 \times 10^{-12} \mathrm{~m}^{2} \mathrm{~s}^{-1}\right.$ in the membrane) in this study can be neglected because of the large Peclet number (ranging from 
$10^{2}$ to $10^{3}$ ). Besides, when assuming diffusion is isotropic, the mass balance of the pseudofirst-order reaction can be integrated as a function of pore axial distance, $\mathrm{z}$, since $u(r)$ is only a function of radius. $k_{\text {obs }}$ refers to rate constant for parent compound degradation (PCB 126).

$$
C(r, z)=C(r, 0) \exp \left[-\frac{k_{\mathrm{obs}} z}{u(r)}\right]
$$

In order to obtain the mean concentration $\bar{C}$ at certain z, a cross-section averaging method was applied to integrate the concentration over the radial dimension as below [60]:

$$
\begin{gathered}
\bar{C}_{\text {final }}=\frac{\int_{0}^{r} C(r, z) u(r) 2 \pi \mathrm{rdr}}{\int_{0}^{r} u(r) 2 \pi \mathrm{rdr}} \\
\bar{C}_{\text {final }}=\frac{2 \bar{C}_{\text {initial }} \int_{u_{0}}^{0} e^{\left(-\frac{k_{\text {obs }} L}{u(r)}\right)} u(r) \mathrm{du}(r)}{u_{0}^{2}}
\end{gathered}
$$

Therefore, the mean outlet concentration $\bar{C}_{\text {final }}(\mathrm{z}=L)$ can be evaluated by the exponential integral:

$$
\bar{C}_{\text {final }}=\frac{\bar{C}_{\text {initial }}\left[\left(k_{\mathrm{obs}} L\right)^{2} E_{1}\left(\frac{k_{\mathrm{obs}} L}{u_{0}}\right)+e^{-\frac{k_{\mathrm{obs}} L}{u_{0}}}\left(u_{0}^{2}-k_{\mathrm{obs}} \mathrm{Lu}_{0}\right)\right]}{u_{0}^{2}}
$$

Substituting $u_{0}$ with $\tau$ :

$$
\bar{C}_{\text {final }}=\frac{\bar{C}_{\text {initial }} \tau^{2}\left[k_{\text {obs }}^{2} E_{1}\left(\frac{k_{\text {obs }} \tau}{2}\right)+e^{-\frac{k_{\text {obs }} \tau}{2}}\left(4 \frac{1}{\tau^{2}}-2 \frac{k_{\text {obs }}}{\tau}\right)\right]}{4}
$$

$$
E_{1}\left(\frac{k_{\mathrm{obs}} \tau}{2}\right)=\int_{\frac{k_{\mathrm{obs}} \tau}{2}}^{\infty} \frac{e^{-t}}{t} \mathrm{dt}
$$

This derived equation (12) can be used to fit $k_{o b s}$ values from the experimental reaction data $\left(\tau, \bar{C}_{\text {initial }}, \bar{C}_{\text {final }}\right)$. For residence time of $7.1 s, 14.7 s$ and $27.0 s, k_{o b s}$ was determined to be $0.359 s^{-1}, 0.317 s^{-1}$ and $0.329 s^{-1}$, respectively. The model indeed verifies that $k_{o b s}$ is indeed independent of $\tau$ and the validity of LFR model. When applied the average $k_{\text {obs }}$ $\left(0.335 \pm 0.018 s^{-1}\right)$ in PFR model, the $\bar{C}_{\text {final }}$ values were $1.39 \mu \mathrm{M}, 0.11 \mu \mathrm{M}$ and $0.002 \mu \mathrm{M}$ compared to $2.28 \mu \mathrm{M}, 0.60 \mu \mathrm{M}$ and $0.05 \mu \mathrm{M}$ obtained from LFR model. Furthermore, the LFR model was used to simulate degradation versus residence time. The smallest root mean 
square of simulated data and experimental results was 0.11 at the $k_{o b s}$ value equal to $0.355 \mathrm{~s}$ ${ }^{-1}$ (Fig. 9). For convective flow, $k_{s a}$ was calculated (from the $k_{o b s}$ value) to be $0.171 \mathrm{~L} \cdot \mathrm{m}^{-2} \mathrm{~h}$ -1 , which is 2.5 times the $k_{s a}$ obtained from the batch study. This result confirmed that the convective flow mode can diminish the influence of mass transfer resistance in degradation experiment.

\subsection{Reusability of Membranes for PCB Degradation}

The feasibility of $\mathrm{Fe} / \mathrm{Pd}$ particle regeneration was already demonstrated by XRD analysis. Reactive membrane reusability in the PCB batch study was investigated by washing and then regenerating the $\mathrm{Fe} / \mathrm{Pd}$ functionalized membranes with $\mathrm{NaBH}_{4}$ after every degradation cycle. All the initial conditions were the same as the first degradation cycle in the batch study. Besides the extent of degradation, the changes of particle size in the membrane surface were also investigated.

The size of the particles in the membrane surface was analyzed by SEM (Fig. S. 9) and then summarized in Fig. 10. The particle size after the fourth regeneration cycle was $26.4 \mathrm{~nm}$ compared to the size $21.6 \mathrm{~nm}$ after first cycle. In the batch reaction mode both diffusion through the membrane and particle reactivity (surface area influence) play a role. James et al [62] found similar surface area normalized rate constants for micro- and nano-sized $\mathrm{Fe}^{0}$ in the treatment of benzoquinone and carbon tetrachloride in the absence of any dopant metal (such as, Pd). In our case, the increase of surface particle size of $22 \%$ resulted in a decrease of $9.7 \%$ PCB conversion for the 4 hours reaction time. The reusability test would suggest that this method has great potential for remediation applications.

\section{Conclusions}

This paper quantified nanoparticle size as a function of membrane pore depth and PCB degradation reaction rate constants through both batch and convective flow (through residence time). The consistency of the membrane permeability in a seven-day test as well as the $\mathrm{pH}$ reversibility behaviors demonstrated that PAA functionalized PVDF membranes were a stable platform for nanoparticles in-situ synthesis. The correlation between nanoparticle size and depth underneath the membrane surface was studied using FIB-SEM. Particle size was uniform inside membrane pores at different depths (particle size: $16.7 \pm 0.7$ $\mathrm{nm}$ ) but slightly smaller than those nanoparticles located on the surface $(19.4 \pm 3.2 \mathrm{~nm})$. However, due to the limitation of the lamella dimensions inherent to the focused ion beam preparation technique (total volume to mill, lamella structural cohesion during thinning, a less than $100 \mathrm{~nm}$ thin lamella sample with the length of 100-1000 times), nanoparticles were characterized to a depth of up to $20 \mu \mathrm{m}$ rather than the entire membrane thickness.

Based on the detailed product analysis, PCB 126 degradation kinetics were investigated in both batch and convective flow modes. An LFR model was used to investigate the reaction rate for a convective flow experiment and simulate the extent of degradation as a function of residence time. The surface area normalized rate constant was found to be $0.171 \mathrm{~L}^{\mathrm{m}} \mathrm{m}^{-2} \mathrm{~h}^{-1}$ in convective flow mode, which is 2.5 times the rate obtained in batch mode. These results confirmed that the convective flow mode can diminish the mass transfer resistance for PCB degradation. 
Regeneration of $\mathrm{Fe} / \mathrm{Pd}$ particles was also investigated, as well as the reusability of particleimmobilized membranes. In XRD analysis, the Fe/Pd particle samples (which were deliberately oxidized and then reduced) exhibited the same crystalline patterns as the original $\mathrm{Fe} / \mathrm{Pd}$ particle samples, thereby demonstrating that $\mathrm{Fe} / \mathrm{Pd}$ particles were successfully regenerated. The membrane maintained reactivity after four PCB degradation cycles with regeneration between each cycle. In order to understand the changes in nanoparticle size during cycles rather than kinetic analysis, nanoparticles size was only measured on the membrane surface. The increase of surface particle size of $22 \%$ resulted in a decrease of 9.7\% PCB conversion for the 4 hours reaction time.

\section{Supplementary Material}

Refer to Web version on PubMed Central for supplementary material.

\section{Acknowledgments}

This research is supported by the NIH-NIEHS-SRC (Award number: P42ES007380). Partial support is also provided by NSF KY EPSCoR grant (Grant no: 1355438). We thank John May and Tricia Coakley from Environmental Research and Training Laboratory (ERTL) at UK for GC-MS and ICP-OES analytical assistance. We also thank Dr. Sony Soman for the assistance with GC-MS analysis for PCB intermediates.

\section{References}

1. Shannon MA, Bohn PW, Elimelech M, Georgiadis JG, Marinas BJ, Mayes AM. Science and technology for water purification in the coming decades. Nature. 2008; 452:301-310. [PubMed: 18354474]

2. Jiang J, Zhu L, Zhu L, Zhu B, Xu Y. Surface characteristics of a self-polymerized dopamine coating deposited on hydrophobic polymer films. Langmuir. 2011; 27:14180-14187. [PubMed: 22011109]

3. Setiawan L, Wang R, Li K, Fane AG. Fabrication of novel poly (amide-imide) forward osmosis hollow fiber membranes with a positively charged nanofiltration-like selective layer. Journal of Membrane Science. 2011; 369:196-205.

4. Luo N, Stewart MJ, Hirt DE, Husson SM, Schwark DW. Surface modification of ethylene-co-acrylic acid copolymer films: Addition of amide groups by covalently bonded amino acid intermediates. Journal of applied polymer science. 2004; 92:1688-1694.

5. Jiang J, Zhang P, Zhu L, Zhu B, Xu Y. Improving antifouling ability and hemocompatibility of poly (vinylidene fluoride) membranes by polydopamine-mediated ATRP. Journal of Materials Chemistry B. 2015; 3:7698-7706.

6. Yin J, Deng B. Polymer-matrix nanocomposite membranes for water treatment. Journal of Membrane Science. 2015; 479:256-275.

7. Bai H, Zan X, Juay J, Sun DD. Hierarchical heteroarchitectures functionalized membrane for high efficient water purification. Journal of Membrane Science. 2015; 475:245-251.

8. A.P.H. Association. Resolution 9304: Recognizing and addressing the environmental and occupational health problems posed by chlorinated organic chemicals. Am J Public Health. 1994; 84:514-515. [PubMed: 8068077]

9. Crane R, Scott T. Nanoscale zero-valent iron: future prospects for an emerging water treatment technology. Journal of hazardous materials. 2012; 211:112-125. [PubMed: 22305041]

10. Fu F, Dionysiou DD, Liu H. The use of zero-valent iron for groundwater remediation and wastewater treatment: a review. Journal of Hazardous Materials. 2014; 267:194-205. [PubMed: 24457611]

11. He F, Zhao D. Hydrodechlorination of trichloroethene using stabilized Fe-Pd nanoparticles: Reaction mechanism and effects of stabilizers, catalysts and reaction conditions. Applied Catalysis B: Environmental. 2008; 84:533-540. 
12. Choi H, Al Abed SR, Agarwal S, Dionysiou DD. Synthesis of reactive nano-Fe/Pd bimetallic system-impregnated activated carbon for the simultaneous adsorption and dechlorination of PCBs. Chemistry of Materials. 2008; 20:3649-3655.

13. Han Y, Yan W. Bimetallic nickel-iron nanoparticles for groundwater decontamination: effect of groundwater constituents on surface deactivation. Water research. 2014; 66:149-159. [PubMed: 25201338]

14. Shu HY, Chang MC, Liu JJ. Reductive decolorization of acid blue 113 azo dye by nanoscale zerovalent iron and iron-based bimetallic particles. Desalination and Water Treatment. 2016; 57:79637975.

15. Elliott DW, Zhang WX. Field assessment of nanoscale bimetallic particles for groundwater treatment. Environmental Science \& Technology. 2001; 35:4922-4926. [PubMed: 11775172]

16. Zhu N, Luan H, Yuan S, Chen J, Wu X, Wang L. Effective dechlorination of HCB by nanoscale $\mathrm{Cu} / \mathrm{Fe}$ particles. Journal of Hazardous Materials. 2010; 176:1101-1105. [PubMed: 19969417]

17. Hoag GE, Collins JB, Holcomb JL, Hoag JR, Nadagouda MN, Varma RS. Degradation of bromothymol blue by 'greener' nano-scale zero-valent iron synthesized using tea polyphenols. Journal of Materials Chemistry. 2009; 19:8671-8677.

18. He F, Zhao D. Manipulating the size and dispersibility of zerovalent iron nanoparticles by use of carboxymethyl cellulose stabilizers. Environmental Science \& Technology. 2007; 41:6216-6221. [PubMed: 17937305]

19. Hudson R, Hamasaka G, Osako T, Yamada YM, Li CJ, Uozumi Y, Moores A. Highly efficient iron (0) nanoparticle-catalyzed hydrogenation in water in flow. Green Chemistry. 2013; 15:2141-2148.

20. Sun YP, Li XQ, Zhang WX, Wang HP. A method for the preparation of stable dispersion of zerovalent iron nanoparticles. Colloids and Surfaces A: Physicochemical and Engineering Aspects. 2007; 308:60-66.

21. Hadjipanayis CG, Bonder MJ, Balakrishnan S, Wang X, Mao H, Hadjipanayis GC. Metallic iron nanoparticles for MRI contrast enhancement and local hyperthermia. Small. 2008; 4:1925-1929. [PubMed: 18752211]

22. Greenlee LF, Rentz NS. ATMP-stabilized iron nanoparticles: chelator-controlled nanoparticle synthesis. Journal of Nanoparticle Research. 2014; 16:1-16.

23. Schrick B, Blough JL, Jones AD, Mallouk TE. Hydrodechlorination of trichloroethylene to hydrocarbons using bimetallic nickel- iron nanoparticles. Chemistry of Materials. 2002; 14:5140 5147.

24. Wang Y, Zhao H, Zhao G. Iron-copper bimetallic nanoparticles embedded within ordered mesoporous carbon as effective and stable heterogeneous Fenton catalyst for the degradation of organic contaminants. Applied Catalysis B: Environmental. 2015; 164:396-406.

25. Rastogi A, Al Abed SR, Dionysiou DD. Sulfate radical-based ferrous-peroxymonosulfate oxidative system for PCBs degradation in aqueous and sediment systems. Applied Catalysis B: Environmental. 2009; 85:171-179.

26. Fang GD, Dionysiou DD, Al Abed SR, Zhou DM. Superoxide radical driving the activation of persulfate by magnetite nanoparticles: implications for the degradation of PCBs. Applied Catalysis B: Environmental. 2013; 129:325-332.

27. Wang CB, Zhang WX. Synthesizing nanoscale iron particles for rapid and complete dechlorination of TCE and PCBs. Environmental science \& technology. 1997; 31:2154-2156.

28. Agarwal S, Al Abed SR, Dionysiou DD, Graybill E. Reactivity of substituted chlorines and ensuing dechlorination pathways of select $\mathrm{PCB}$ congeners with $\mathrm{Pd} / \mathrm{Mg}$ bimetallics. Environmental science \& technology. 2008; 43:915-921.

29. Agarwal S, Al Abed SR, Dionysiou DD. A feasibility study on Pd/Mg application in historically contaminated sediments and PCB spiked substrates. Journal of hazardous materials. 2009; 172:1156-1162. [PubMed: 19709811]

30. Agarwal S, Al Abed SR, Dionysiou DD. Enhanced corrosion-based Pd/Mg bimetallic systems for dechlorination of PCBs. Environmental science \& technology. 2007; 41:3722-3727. [PubMed: 17547203] 
31. Doyle JG, Miles T, Parker E, Cheng IF. Quantification of total polychlorinated biphenyl by dechlorination to biphenyl by $\mathrm{Pd} / \mathrm{Fe}$ and $\mathrm{Pd} / \mathrm{Mg}$ bimetallic particles. Microchemical Journal. 1998; 60:290-295.

32. Choi H, Al Abed SR. Effect of reaction environments on the reactivity of PCB (2-chlorobiphenyl) over activated carbon impregnated with palladized iron. Journal of hazardous materials. 2010; 179:869-874. [PubMed: 20388583]

33. Gui M, Ormsbee LE, Bhattacharyya D. Reactive functionalized membranes for polychlorinated biphenyl degradation. Industrial \& engineering chemistry research. 2013; 52:10430-10440. [PubMed: 24954974]

34. Lewis SR, Datta S, Gui M, Coker EL, Huggins FE, Daunert S, Bachas L, Bhattacharyya D. Reactive nanostructured membranes for water purification. Proceedings of the National Academy of Sciences. 2011; 108:8577-8582.

35. He F, Zhao D, Paul C. Field assessment of carboxymethyl cellulose stabilized iron nanoparticles for in situ destruction of chlorinated solvents in source zones. Water Research. 2010; 44:23602370. [PubMed: 20106501]

36. Nollet H, Roels M, Lutgen P, Van der Meeren P, Verstraete W. Removal of PCBs from wastewater using fly ash. Chemosphere. 2003; 53:655-665. [PubMed: 12962715]

37. Tu C, Teng Y, Luo Y, Li X, Sun X, Li Z, Liu W, Christie P. Potential for biodegradation of polychlorinated biphenyls (PCBs) by Sinorhizobium meliloti. Journal of hazardous materials. 2011; 186:1438-1444. [PubMed: 21195547]

38. Yang YN, Jun W, Qing Zhu Z, Xue Si C, Hui Xuan Z. The research of rheology and thermodynamics of organic-inorganic hybrid membrane during the membrane formation. Journal of Membrane Science. 2008; 311:200-207.

39. Greenlee LF, Rentz NS. Influence of nanoparticle processing and additives on PES casting solution viscosity and cast membrane characteristics. Polymer. 2016

40. Pang R, Li J, Wei K, Sun X, Shen J, Han W, Wang L. In situ preparation of Al-containing PVDF ultrafiltration membrane via sol-gel process. Journal of colloid and interface science. 2011; 364:373-378. [PubMed: 21955802]

41. Li X, Pang R, Li J, Sun X, Shen J, Han W, Wang L. In situ formation of Ag nanoparticles in PVDF ultrafiltration membrane to mitigate organic and bacterial fouling. Desalination. 2013; 324:48-56.

42. Li X, Sotto A, Li J, Van der Bruggen B. Progress and perspectives for synthesis of sustainable antifouling composite membranes containing in situ generated nanoparticles. Journal of Membrane Science. 2016

43. Lin YH, Tseng HH, Wey MY, Lin MD. Characteristics, morphology, and stabilization mechanism of PAA250K-stabilized bimetal nanoparticles. Colloids and Surfaces A: Physicochemical and Engineering Aspects. 2009; 349:137-144.

44. Hu K, Dickson JM. Modelling of the pore structure variation with $\mathrm{pH}$ for pore-filled $\mathrm{pH}$-sensitive poly (vinylidene fluoride)-poly (acrylic acid) membranes. Journal of Membrane Science. 2008; 321:162-171.

45. Hu K, Dickson JM. Development and characterization of poly (vinylidene fluoride)-poly (acrylic acid) pore-filled pH-sensitive membranes. Journal of Membrane Science. 2007; 301:19-28.

46. Gu Y, Favier I, Pradel C, Gin DL, Lahitte JF, Noble RD, Gómez M, Remigy JC. High catalytic efficiency of palladium nanoparticles immobilized in a polymer membrane containing poly (ionic liquid) in Suzuki-Miyaura cross-coupling reaction. Journal of Membrane Science. 2015; 492:331339.

47. Kim J, Fu Q, Xie K, Scofield JM, Kentish SE, Qiao GG. CO 2 separation using surfacefunctionalized $\mathrm{SiO} 2$ nanoparticles incorporated ultra-thin film composite mixed matrix membranes for post-combustion carbon capture. Journal of Membrane Science. 2016; 515:54-62.

48. Huang L, Zhao S, Wang Z, Wu J, Wang J, Wang S. In situ immobilization of silver nanoparticles for improving permeability, antifouling and anti-bacterial properties of ultrafiltration membrane. Journal of Membrane Science. 2016; 499:269-281.

49. Kim CS, Ahn SH, Jang DY. Review: Developments in micro/nanoscale fabrication by focused ion beams. Vacuum. 2012; 86:1014-1035. 
50. Reyntjens S, Puers R. A review of focused ion beam applications in microsystem technology. Journal of Micromechanics and Microengineering. 2001; 11:287.

51. Xu J, Bhattacharyya D. Modeling of Fe/Pd nanoparticle-based functionalized membrane reactor for PCB dechlorination at room temperature. The Journal of Physical Chemistry C. 2008; 112:9133-9144.

52. Gui M, Papp JK, Colburn AS, Meeks ND, Weaver B, Wilf I, Bhattacharyya D. Engineered iron/ iron oxide functionalized membranes for selenium and other toxic metal removal from power plant scrubber water. Journal of membrane science. 2015; 488:79-91. [PubMed: 26327740]

53. Groll J, Ademovic Z, Ameringer T, Klee D, Moeller M. Comparison of Coatings from Reactive Star Shaped PEG-s tat-PPG Prepolymers and Grafted Linear PEG for Biological and Medical Applications. Biomacromolecules. 2005; 6:956-962. [PubMed: 15762665]

54. Zhang W, Wahlgren M, Sivik B. Membrane characterization by the contact angle technique: II. Characterization of UF-membranes and comparison between the captive bubble and sessile drop as methods to obtain water contact angles. Desalination. 1989; 72:263-273.

55. Baek Y, Kang J, Theato P, Yoon J. Measuring hydrophilicity of RO membranes by contact angles via sessile drop and captive bubble method: A comparative study. Desalination. 2012; 303:23-28.

56. Kanel SR, Manning B, Charlet L, Choi H. Removal of arsenic (III) from groundwater by nanoscale zero-valent iron. Environmental science \& technology. 2005; 39:1291-1298. [PubMed: 15787369]

57. Petla RK, Vivekanandhan S, Misra M, Mohanty AK, Satyanarayana N. Soybean (Glycine max) leaf extract based green synthesis of palladium nanoparticles. 2011

58. Saratchandran A D, KM S, KV R, Cherupally Krishnan Krishnan N. D-aminoacid oxidase- $\mathrm{Fe}_{2} \mathrm{O}_{3}$ nanoparticle complex mediated antitumor activity in Swiss albino mice. Journal of Cancer Therapy. 2011; 2011

59. Yang C, Nuxoll EE, Cussler E. Reactive barrier films. AIChE journal. 2001; 47:295-302.

60. Davis, ME., Davis, RJ. International. McGraw-Hill; Boston: 2003. Fundamentals of chemical reaction engineering; p. 260-262.

61. Chen, NH. Process reactor design. Allyn and Bacon; Boston: 1983. p. 297-299.

62. Nurmi JT, Tratnyek PG, Sarathy V, Baer DR, Amonette JE, Pecher K, Wang C, Linehan JC, Matson DW, Penn RL. Characterization and properties of metallic iron nanoparticles: spectroscopy, electrochemistry, and kinetics. Environmental Science \& Technology. 2005; 39:1221-1230. [PubMed: 15787360] 


\section{Polymer solution}
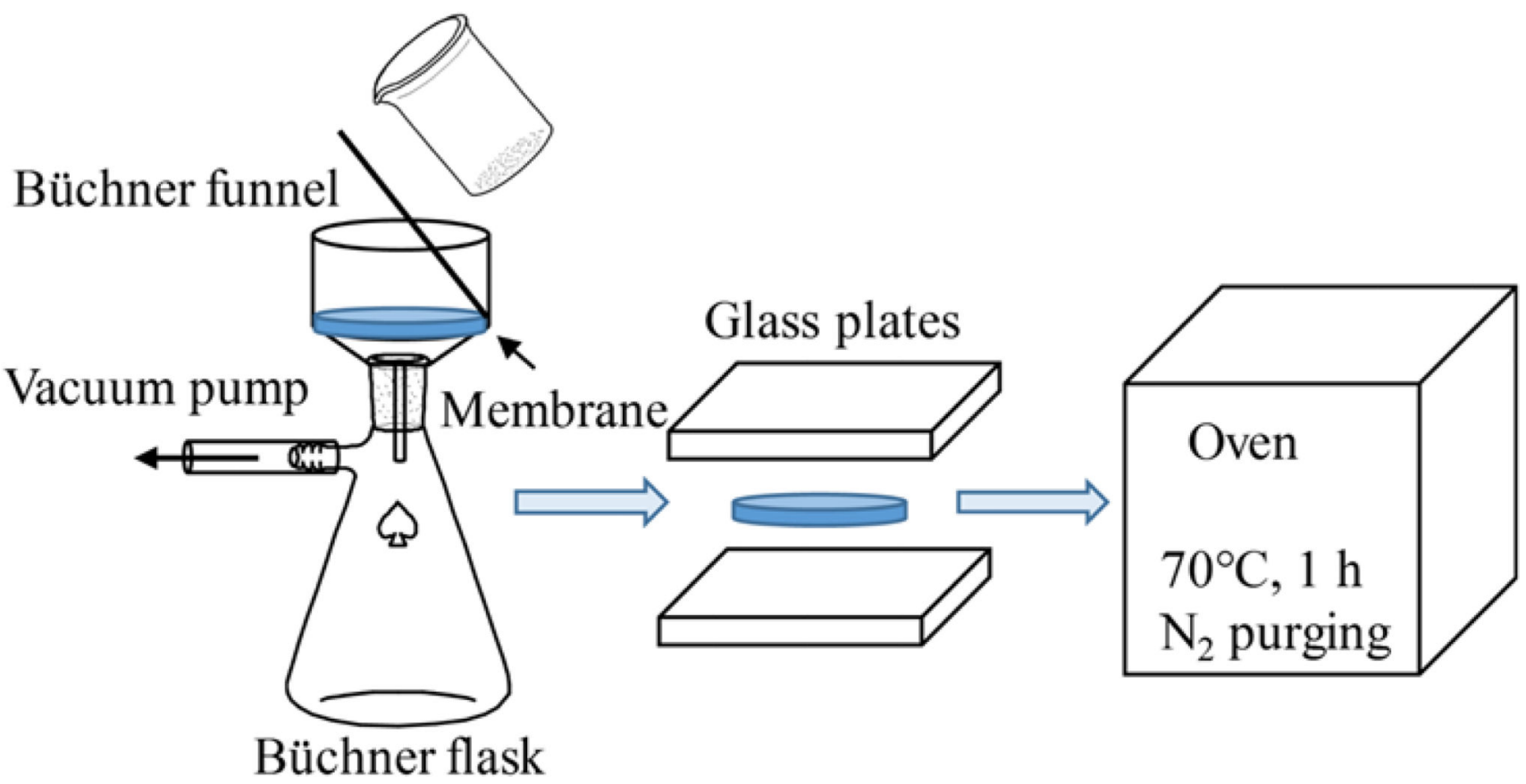

Fig. 1.

Schematic of membrane functionalization method. 
Specific Aims:

1. Synthesis of functionalized membranes

2. Properties of nanoparticles characterized versus the depth

3. PCB Degradation kinetics and modeling simulation

4. Reusability of functionalized membrane in PCB degradation

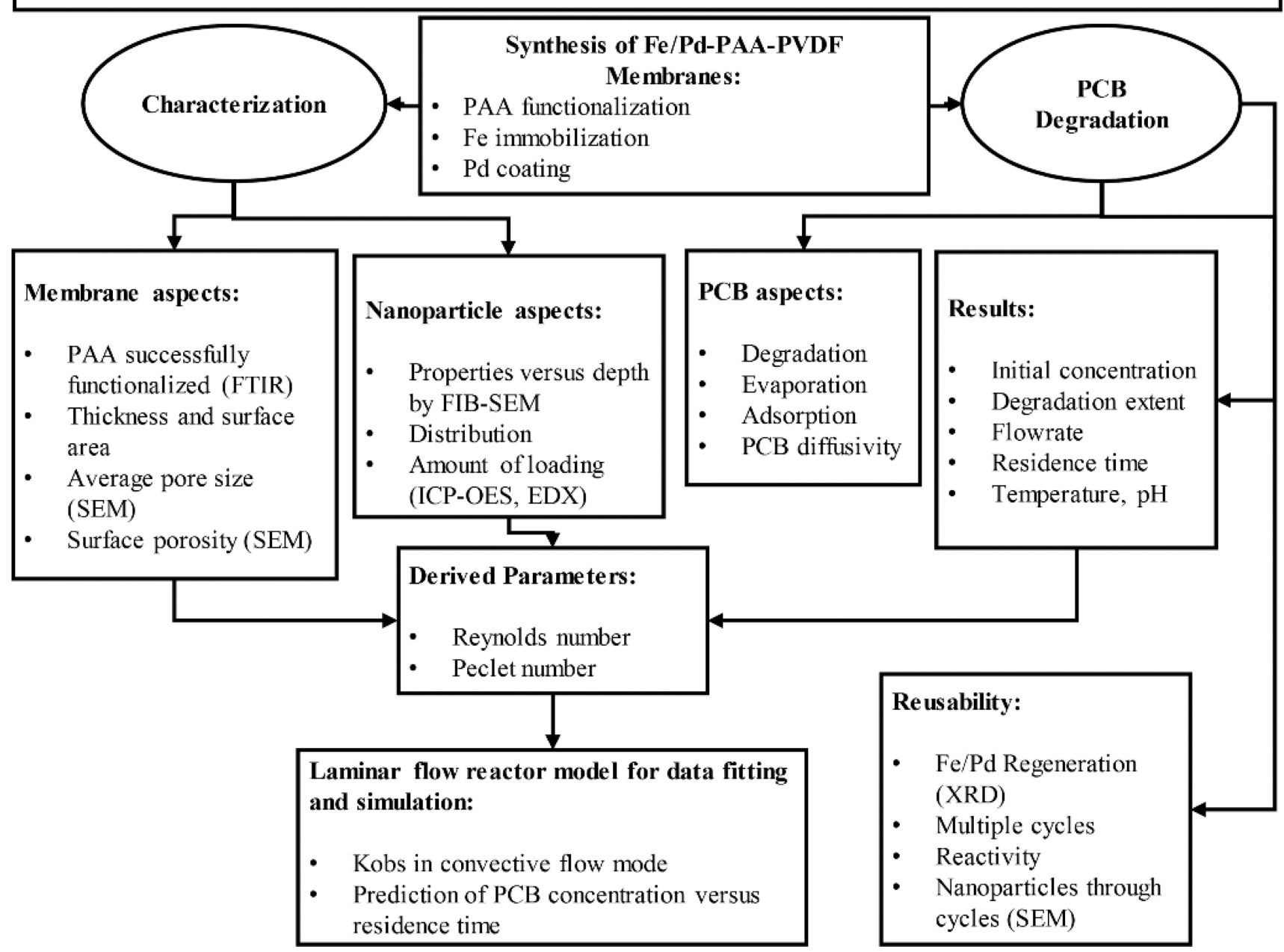

Fig. 2.

Schematic of aims and processes. 

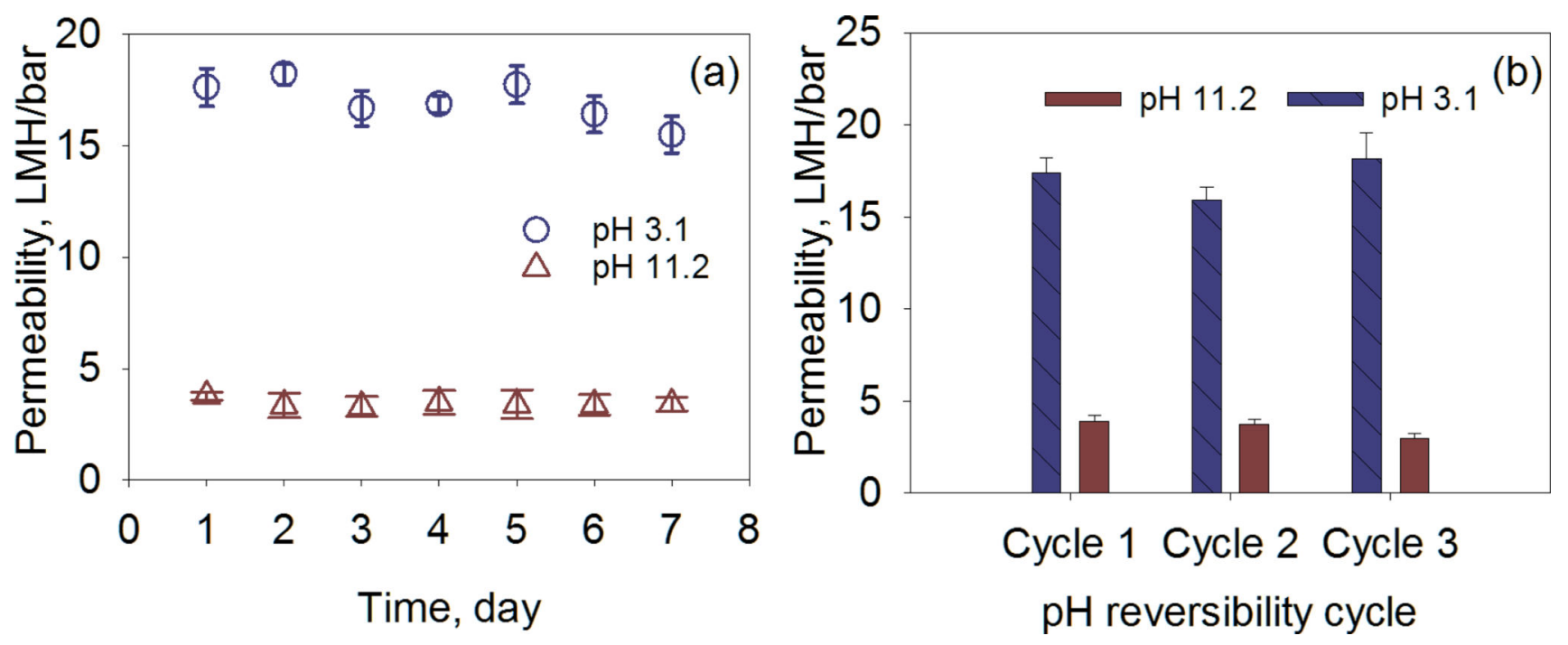

Fig. 3.

PAA functionalized full scale PVDF 700 membrane (13.1 wt \% PAA, 1 mol \% initiator and 1 mol \% cross-linker): (a) long term permeability test; (b) $\mathrm{pH}$ reversibility study. At both acid ( $\mathrm{pH} 3.1)$ and base $(\mathrm{pH} 11.2)$ environment and operating pressure remained at 2.76 bar $\left(22^{\circ} \mathrm{C}\right)$. 

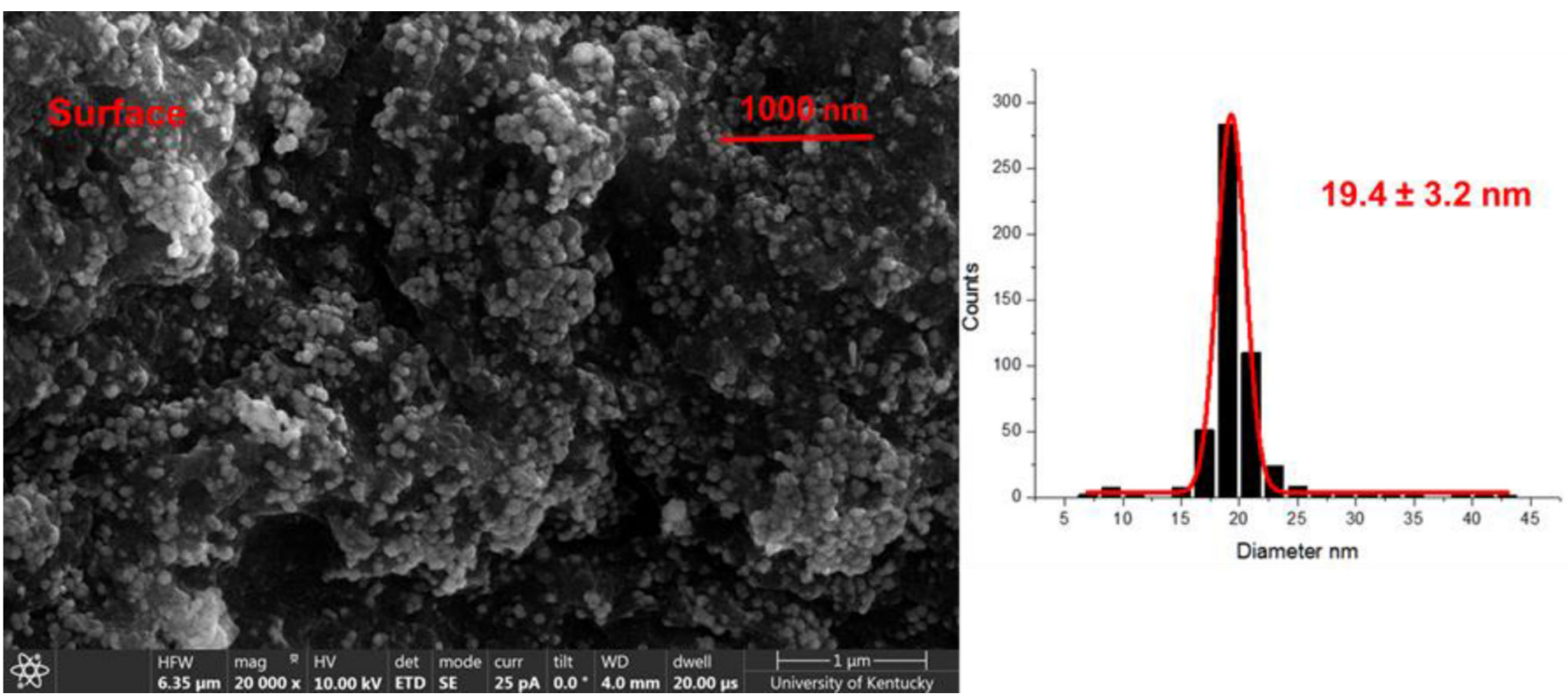

Fig. 4.

FIB-SEM image of the surface on the Fe/Pd-PAA-PVDF 700 membrane (13.4 wt \% PAA, 1 mol \% initiator and $1 \mathrm{~mol} \%$ of cross-linker, $4.1 \mathrm{mg} \mathrm{Fe}, 1.3 \mathrm{wt} \% \mathrm{Pd}$ ) and the summary of observed Fe/Pd nanoparticles (more than 500 counts). 

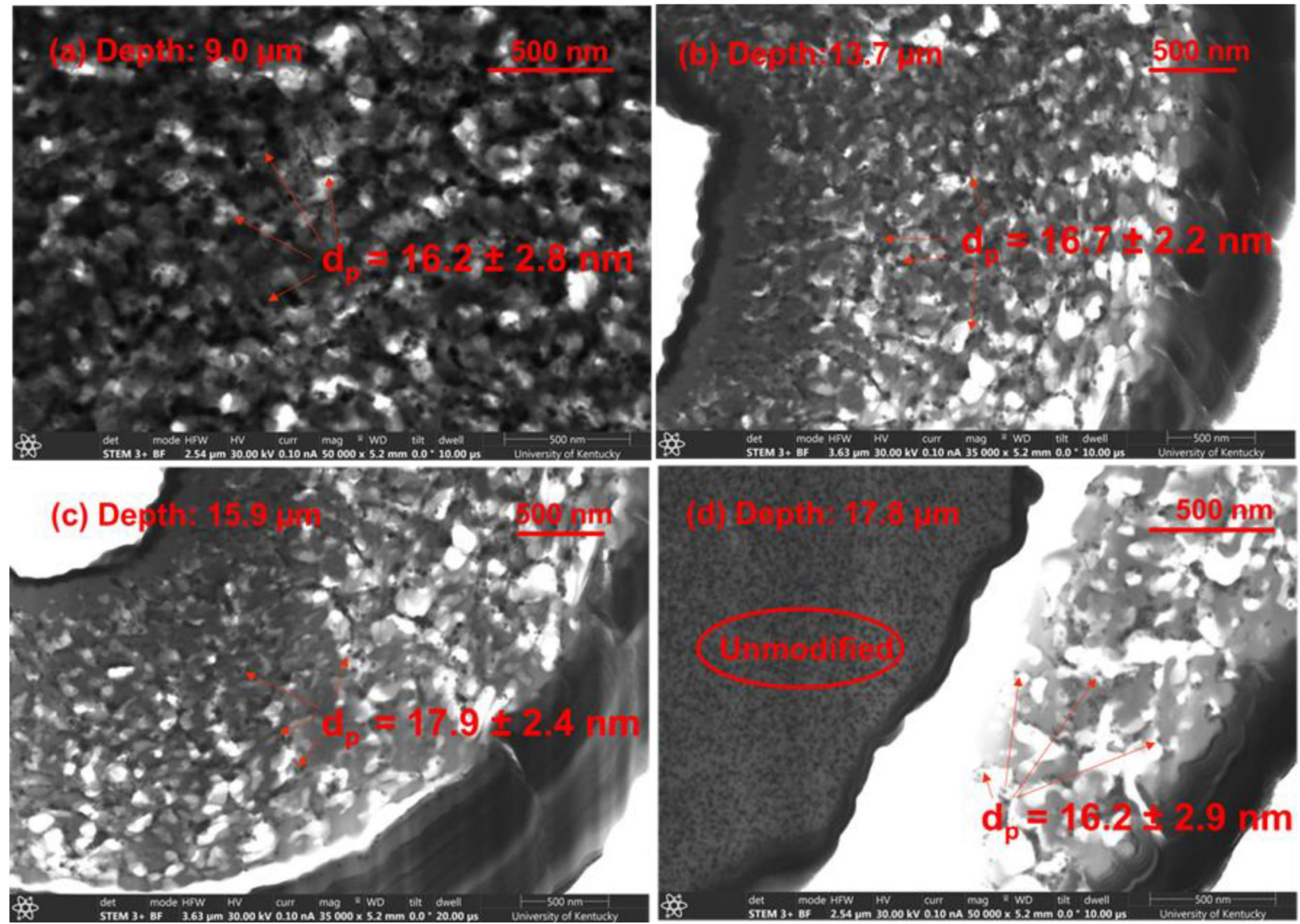

Fig. 5.

FIB-SEM image of Fe/Pd-PAA-PVDF 700 membrane interior (13.4 wt \% PAA, 1 mol \% initiator and $1 \mathrm{~mol} \%$ of cross-linker, $4.1 \mathrm{mg} \mathrm{Fe}, 1.3 \mathrm{wt} \% \mathrm{Pd}$ ). Image (a) to (d) were observed in the different depths of lamella sample (Fig. S. 4 (b)), which cut from the membrane sample (Fig. S. 4 (a)). The unmodified area in image (d) means this part of the sample was not modified (thinned) by FIB for electron transparency. 


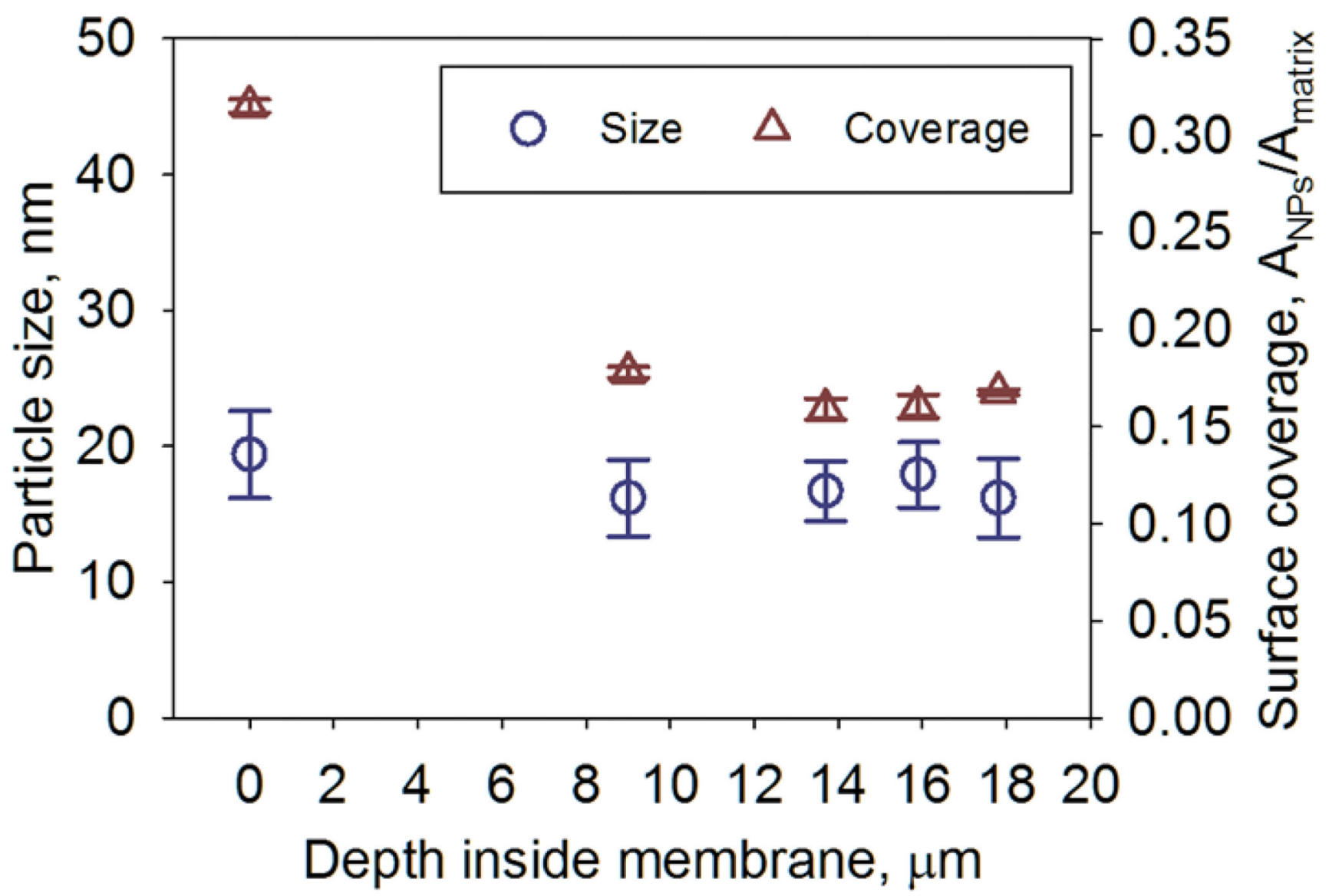

Fig. 6.

Correlation between Fe/Pd nanoparticle size, surface coverage (nanoparticle occupation of the membrane matrix) and depth under the membrane surface (more than 200 counts selected for each sample). 


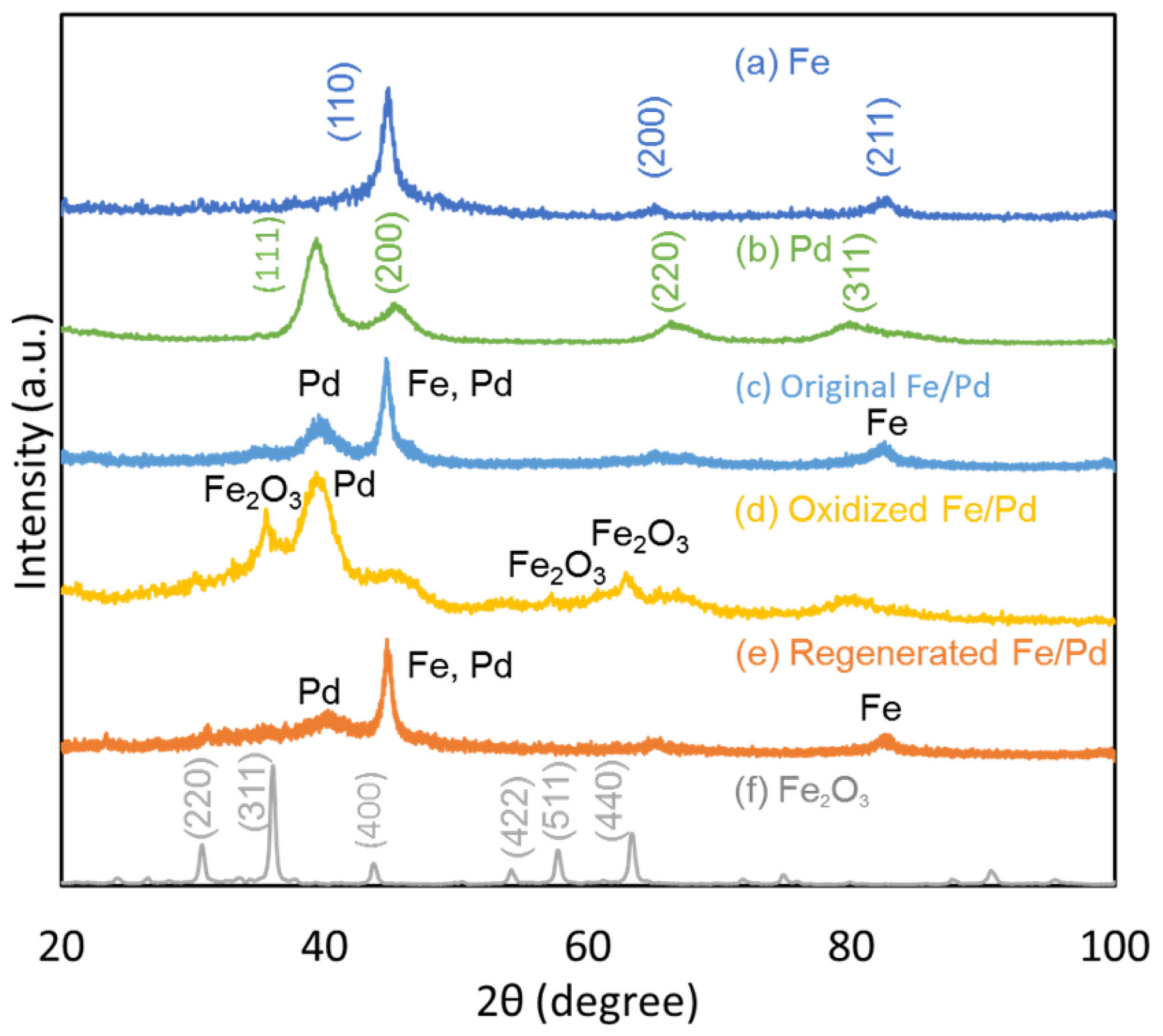

Fig. 7.

An XRD diffractogram of (a) freshly made metallic iron $\left(\mathrm{Fe}^{0}\right)$ particles, (b) freshly made palladium particles, (c) palladium coated iron particles, (d) deliberately oxidized $\mathrm{Fe} / \mathrm{Pd}$ particles, (e) regenerated Fe/Pd particles and (f) $\mathrm{Fe}_{2} \mathrm{O}_{3}$ particles (Sigma Aldrich). 


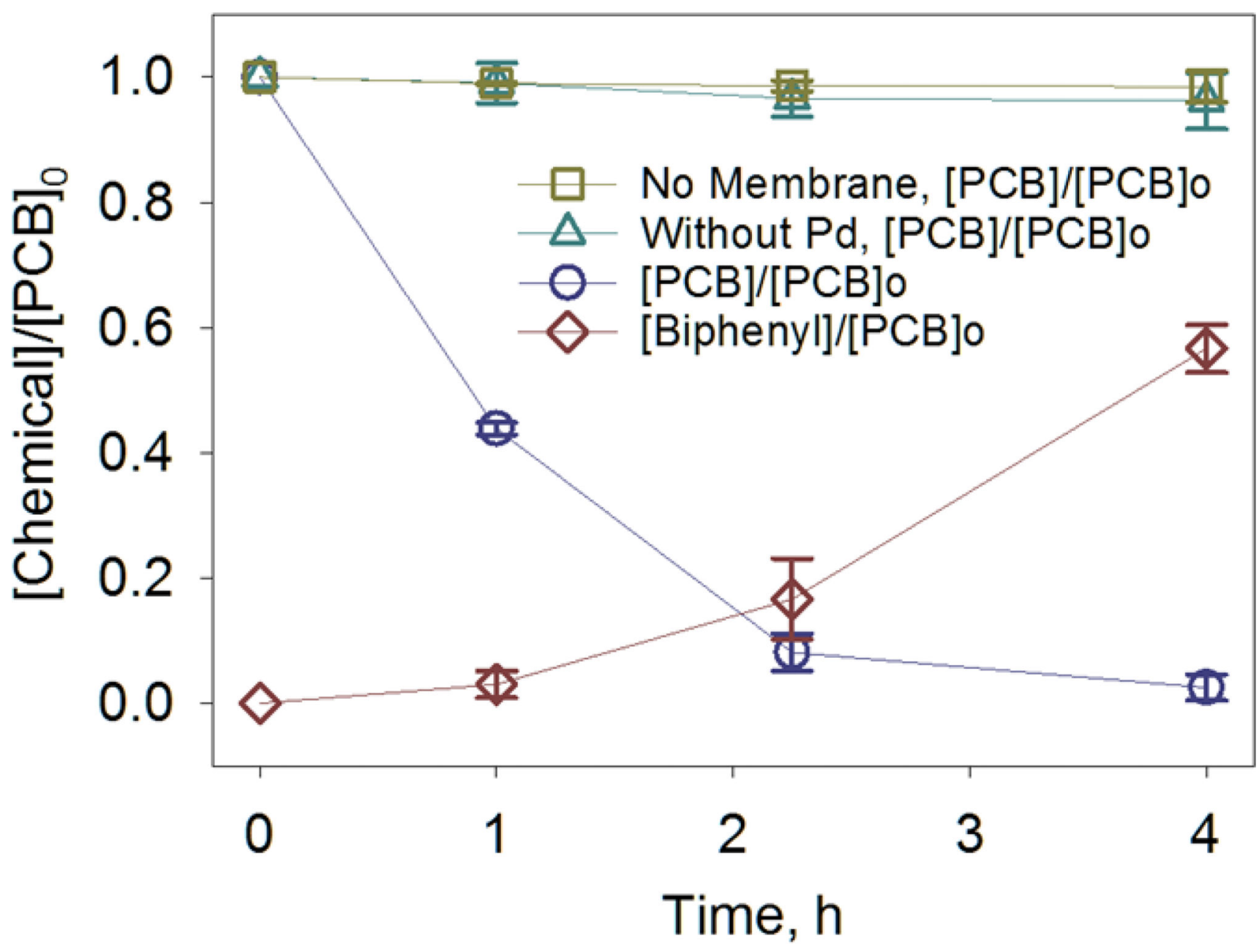

Fig. 8.

Batch study of PCB 126 degradation and biphenyl formation by Fe/Pd-PAA-PVDF 700 membranes. $[\mathrm{PCB} 126]_{0}=15 \mu \mathrm{M},[\mathrm{Fe}]=0.41 \mathrm{~g} / \mathrm{L},[\mathrm{Pd}]=1.3 \mathrm{wt} \%$ as $\mathrm{Fe}, \mathrm{pH}=5.5, \mathrm{~T}=$ $22^{\circ} \mathrm{C}$. 


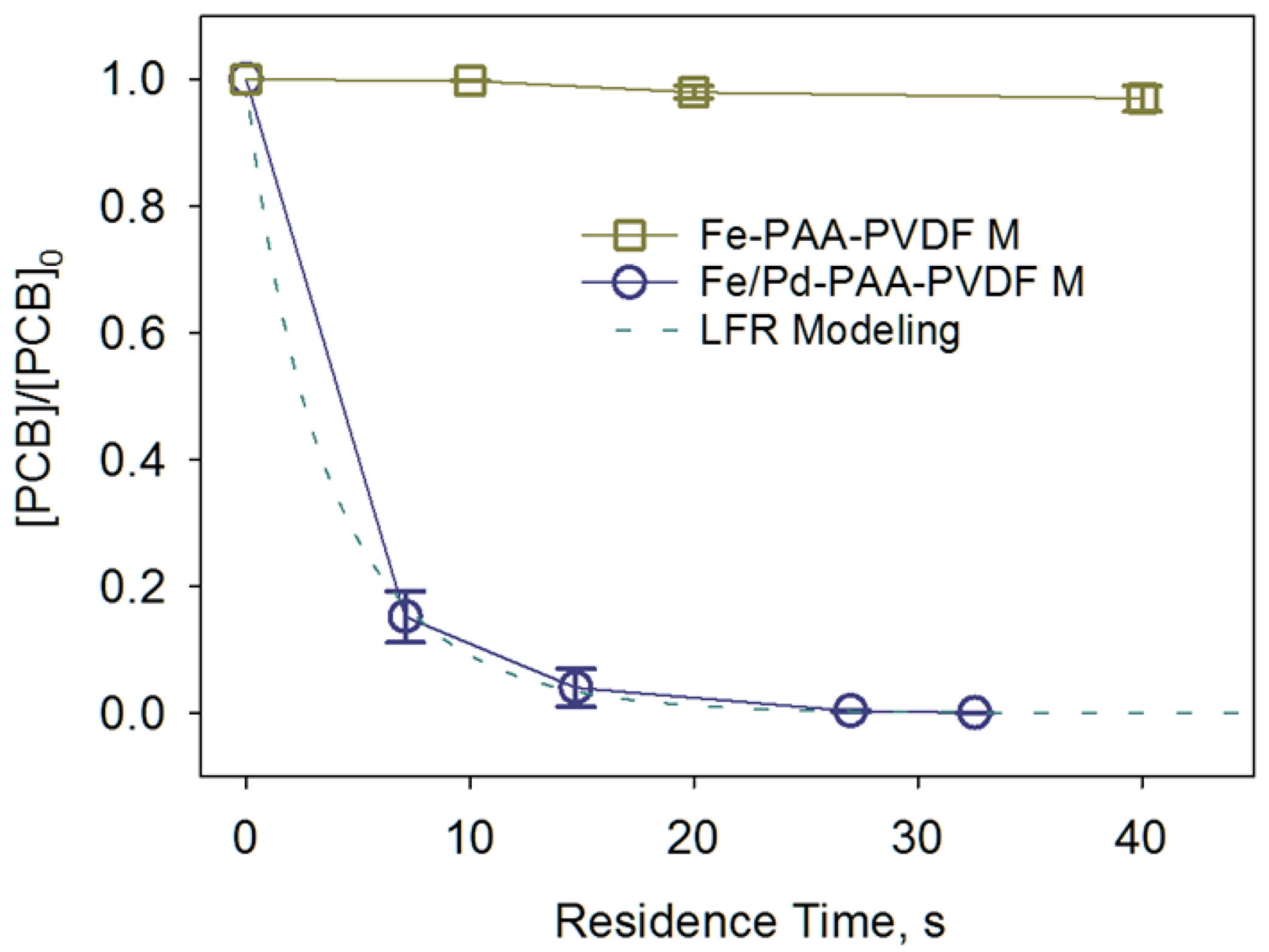

Fig. 9.

Convective flow study of PCB 126 degradation by Fe/Pd-PAA-PVDF 700 membranes. FePAA-PVDF membrane served as blank control group and laminar flow reactor model was used for experimental data fitting. Effective surface area: $13.2 \mathrm{~cm}^{2}$. $[\mathrm{PCB}]_{0}=15 \mu \mathrm{M}, 4.1 \mathrm{mg}$ Fe per membrane, $[\mathrm{Pd}]=1.3 \mathrm{wt} \%$ as $\mathrm{Fe}, \mathrm{pH}=5.5, \mathrm{~T}=22^{\circ} \mathrm{C}$. 


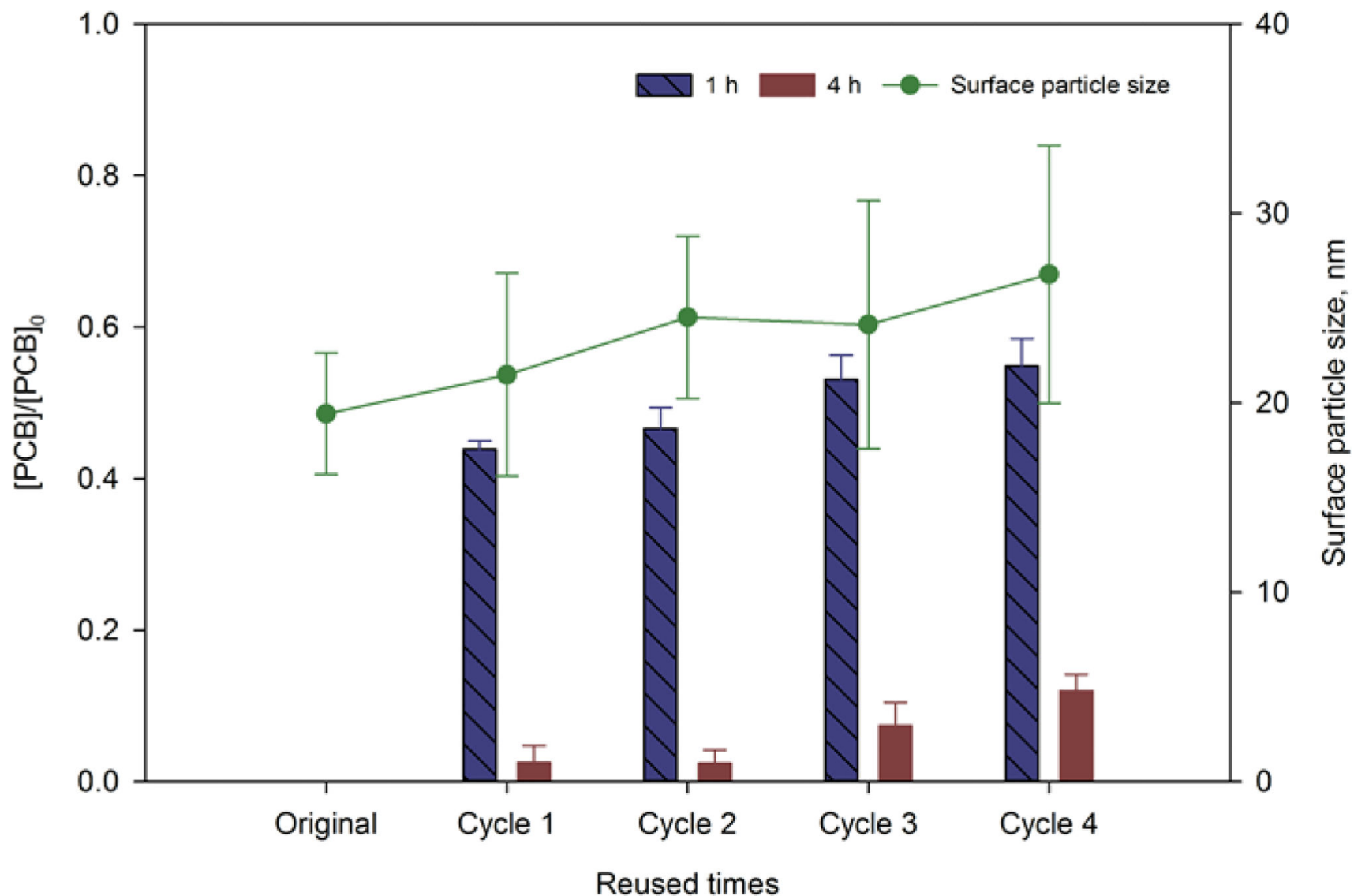

Fig. 10.

Reusability test for PCB 126 degradation in batch study. Degradation results and the changes of $\mathrm{Fe} / \mathrm{Pd}$ particles size (on the membrane surface) during cycles. $[\mathrm{PCB}]_{0}=15 \mu \mathrm{M},[\mathrm{Fe}]=$ $0.41 \mathrm{~g} / \mathrm{L},[\mathrm{Pd}]=1.3 \mathrm{wt} \%$ as $\mathrm{Fe}, \mathrm{pH}=5.5, \mathrm{~T}=22^{\circ} \mathrm{C}$. 

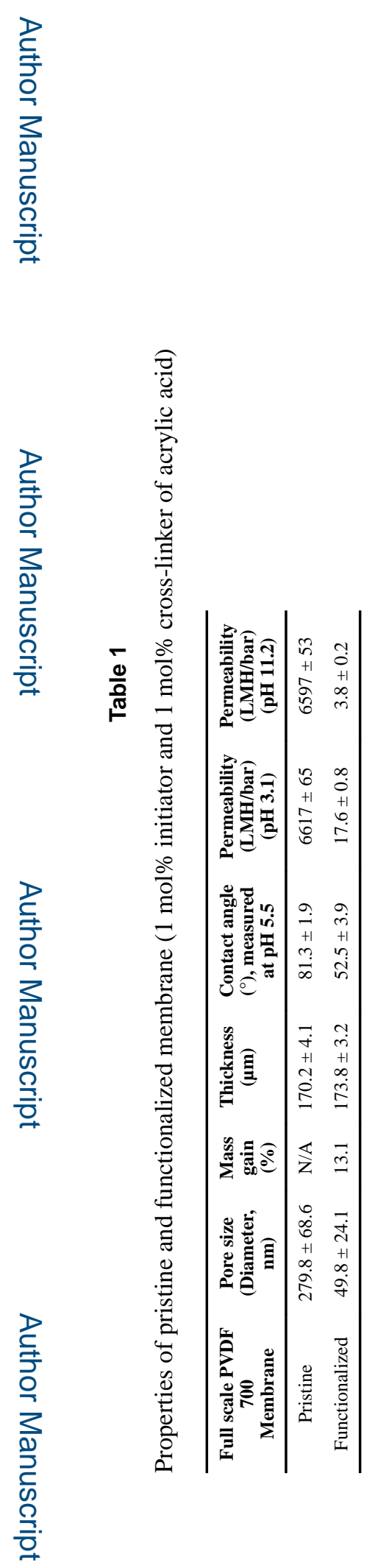

J Memb Sci. Author manuscript; available in PMC 2018 May 15. 